\title{
The Nishnaabemwin Restructuring Controversy: New Empirical Evidence
}

\section{Introduction}

The deletion of unstressed vowels from iterative feet, or rhythmic syncope, has attracted interest in phonological theory because serial theories of phonology can generate it, while parallel theories cannot (see McCarthy 2008 and Bowers and Hao 2018; see Kager 1997 and Blumenfeld 2006 for attempted parallelist solutions). A more fundamental question is whether language learners acquire rhythmic syncope. This paper details the recent development of Nishnaabemwin (a collective name for the Odawa and Eastern Ojibwe dialects of Ojibwe, Algonquian, United States and Canada), where phonetic unstressed vowel reduction came to the cusp of phonological rhythmic syncope (Bloomfield 1957). That is, the word for 'shoe', which was historically [(mskí)(zín)], came to be pronounced as $\left.\left(\mathrm{m}^{\curvearrowright} \mathrm{kí}\right)(\mathrm{zín})\right]$, while the possessed form [(nI-mí)(kızín)] 'my shoe' was pronounced $\left[\left(\mathrm{n}^{\supset}-\mathrm{m} \hat{\Lambda}\right)\left(\mathrm{k}^{\supset} \mathrm{zín}\right)\right]$. Nishnaabemwin reportedly underwent a dramatic restructuring instead of maintaining the incipient rhythmic deletion alternations (Piggott 1980 [1974], Kaye 1974, Rhodes 1975; 1976; 1985a; 1985b). The abandonment of the vowel-zero alternations may be evidence that learners have difficulty with rhythmic syncope.

Unfortunately, strong conclusions cannot be drawn from the existing literature, as the descriptive facts are somewhat incomplete. Early work strongly suggests that the restructuring was initiated by the first cohort that was exposed to incipient deletion, and that all members of that cohort adopted the restructuring (Piggot 1980[1974], Rhodes 1975; 1985a; 1985b). If true, rhythmic deletion may pose enough of a challenge to learners that they simply reject it. However, the original reports do not conclusively demonstrate cohort-wide restructuring, and later authors have suggested that the restructuring was neither immediate, nor cohortwide (Valentine 1994; 2001). Furthermore, attrition is a potential competing explanation for the change, rather than an inherent difficulty with rhythmic deletion (Valentine 1994; 2001).

We seek to resolve these uncertainties with three surveys of the first cohort of speakers born during the original incipient deletion period. The first two surveys confirm the original restructuring reports: no speakers prefer the rhythmic syncope patterns. The third survey shows that the participants have accurate knowledge of the original alternating paradigms, which suggests that the restructuring was not due to attrition. 
In the following sections, we situate the restructuring in the context of the initial rhythmic near-syncope system and highlight areas of uncertainty in the descriptive literature (section 2). In section 3 we introduce the methodology used in the surveys reported here. Section 4 discusses the first survey, which shows that innovative prefixes like nd $\Lambda^{-}$or ndo:- have proliferated far beyond their historical distribution. Section 5 discusses the second survey, which affirms that innovative prefixation with non-alternating paradigms are now preferred. Section 6 discusses the third survey, which shows that the participants can distinguish between conservative forms and non-existent foils; in other words, the restructuring cohort prefers innovative patterns despite having accurate knowledge of the conservative pattern. Section 7 moves beyond the set of surface forms in Nishnaabemwin and argues that the grammar of modern Nishnaabemwin does not recapitulate the historical rhythmic syncope process. Section 8 concludes by considering the ramifications of the observed instability for phonological theory.

\section{Background}

This section provides background on the rejected historical pattern, and also outlines gaps in our understanding of the innovative variety. Specifically, section 2.1 illustrates the original severe reduction system, section 2.2 outlines the modern variety of Nishnaabemwin, section 2.3 establishes that the modern variety is the immediate successor to the original severe reduction system, and section 2.5 outlines gaps in our understanding of the modern system.

\subsection{0's Nishnaabemwin}

This section illustrates key aspects of Nishnaabemwin as it was spoken in the late 1930's. Crucially, adult speakers in the 1930's represented unstressed vowels phonologically, but reduced them phonetically. Furthermore, though the severe reduction was not quite total deletion, it was liable to be perceived as such, and the subsequent generation evidently did perceive reduction as deletion.

The precursor to rhythmic syncope, the severe phonetic reduction of unstressed vowels, was first documented in Nishnaabemwin by Bloomfield in the late 1930's. Bloomfield reported that "the vowels of [...] odd-numbered" light syllables were reduced, where the count goes from left to right, restarts after long vowels, and ignores the final syllable (Bloomfield 1957:5). The alternating reduction matches the uncontroversial iambic stress pattern common in Ojibwe dialects (Valentine 
1994), which places odd-numbered light syllables in the weak branch of the foot. Specifically, the typical Ojibwe dialect has iteratively assigned left-aligned iambs, with otherwise unparseable final syllables placed in a degenerate foot. While syllables with long vowels are always heavy, closed syllables are not. With reduction grafted to this stress pattern, a word like the name for the language, which had

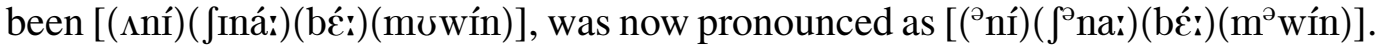

Importantly, person prefixes were part of the domain for footing. This gave rise to paradigmatic alternations, which provided evidence of an active reductioncum-deletion process, as shown in (1). Note that phonological mappings are presented in rule-based derivations because they are a compact and comprehensible way to illustrate phonological mappings, not because derivations are assumed to be theoretically desirable (see Bowers and Hao 2018 for an illustration of how alternating vowel deletion can be directly transduced). To clarify which stage of Nishnaabemwin is under discussion, examples are labeled with the stage of Nishnaabemwin they represent. ${ }^{1}$

\begin{tabular}{|c|c|c|}
\hline ff he kicks him' & 'I kick him' & 1930’s \\
\hline$-\mathrm{d} /$ & /nI-d $\Lambda$ JgI $\int k \Lambda \mathrm{w}-\mathrm{a}: /$ & UR \\
\hline )(kıwád) & (nIdíg)(gIfkń)(wá:) & Stress \\
\hline f) $\left(\mathrm{k}^{\curvearrowright}\right.$ wárd $)$ & 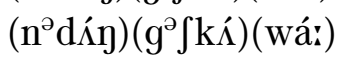 & Reduction \\
\hline $\left.\int\right)\left(k^{\curvearrowright}\right.$ wá:t $)$ & & Other rules \\
\hline${ }^{\ominus}$ ygíf $\left[k^{\ominus}\right.$ wá:t] & [nº́ngg Jkńwá:] & SR \\
\hline
\end{tabular}

Such alternations were quite well attested in the lexicon, with approximately $40 \%$ of the words listed in Rhodes (1985a) beginning historically with a light syllable, and approximately $25 \%$ of the words beginning with more than one light syllable. Similar figures obtain for more recent dictionaries of Nishnaabemwin (Corbiere and Valentine 2016) and dictionaries of non-syncopated dialects of Ojibwe (Nichols and Nyholm 1995, Nichols 2015).

\footnotetext{
${ }^{1}$ Transcriptions in this paper are an IPA transliteration of the orthography used in Rhodes (1985a, see also Valentine 2001:34-49). The orthography accurately represents the phonemes of Nishnaabemwin, but is fairly conservative, reflecting vowel deletion but not subsequent adjustments to the resulting consonant clusters. We use this broad phonemic representation, rather than narrowly transcribing modern surface forms, in order to maximize the comparability of the modern forms to the transitional 1930's forms. Stress is marked for transcriptions of 1930's forms, but not for subsequent reanalyses or restructured forms, since with the loss of unstressed syllables, there is no prominence contrast between unstressed and secondarily stressed syllables. See Bloch (1938), Rhodes (1985b:468-469), Rhodes and Welcher (1996), and Valentine (2001:ch 2) for information on narrow transcriptions of both modern and 1930's Nishnaabemwin.
} 


\subsubsection{Hiatus Resolution}

We digress briefly to preview another process that will figure prominently in the reanalyses discussed in section 2.2. Like all Ojibwe dialects and many Algonquian languages, 1930's Nishnaabemwin had a vowel hiatus resolution process that inserted [d] between V-V sequences that spanned the prefix-stem boundary. Hiatus resolution was a well-established phonological process in Nishnaabemwin prior to the development of reduction, supporting an early placement in the derivation in (2).

\begin{tabular}{|c|c|}
\hline 'My sacred story' & 1930’s \\
\hline /nI-a:diso:ka:n/ & UR \\
\hline $\mathrm{nI}[\mathrm{d}] \mathrm{a}$ diso:ka:n & Hiatus Resolution \\
\hline (nidá:)(disó:)(ká:n) & Stress \\
\hline (n dá:)(dº́:)(ká:n) & Reduction \\
\hline [nºdá:dsó:ká:n] & SR \\
\hline
\end{tabular}

\subsubsection{Severe Reduction in 1930's was at Cusp of Phonological Deletion}

Although the alternating stress pattern forms an uncontroversial part of the 1930's phonology, reduction was a gradient phonetic process when Bloomfield encountered it. According to Bloomfield (1957:5) reduced vowels were primarily "rapidly spoken and often whispered or entirely omitted". However, the reduced vowels also optionally had "more distinct forms" (ibid) that reflected their underlying quality, as seen in the contrast between /I-nin $\widehat{d_{3}} / \rightarrow\left[\left({ }^{\mathrm{I} n i ́ n t} \widehat{\mathrm{f}}\right)\right]$ 'someone's hand' and $/ \mho$-nind $\widehat{z} / \rightarrow\left[\left({ }^{\mho}\right.\right.$ nínt $\left.\left.\widehat{f}\right)\right]$ 'his hand' (ibid:6). Bloomfield further reports that all of the reported phonetic variants could occur "even in utterances of one and the same form" (ibid). This gradience was corroborated by Bernard Bloch's parallel transcriptions of Bloomfield's elicitation sessions (Bloch 1938).

Following Bloomfield's description, the reduced vowels were not yet phonologically deleted. If they were truly deleted, the underlying quality of the reduced vowels could never surface in forms like [('nínt $\left.\left.\int\right)\right]$ 'his hand', as that information would be absent from the phonetic representation. The most appropriate analysis of the 1930's reduction is that it was phonetic underarticulation of unstressed vowels, which usually tended towards a null value.

While it is not currently known when first language learners classify severely reduced segments as categorically deleted, presumably there is some point where such a decision is taken. Note that the assumption of a categorical threshold is 
standardly made to explain the phonologization of categorical processes from gradient phonetics (Bermúdez-Otero 2007; 2014). Importantly, the threshold could be either an absolute value (e.g. a segment is absent if the adjacent segments are separated by no more than a particular number of milliseconds some percentage of the time) or could be relative to language-particular values (e.g. a vowel is absent if the adjacent consonants are separated by no more than $25 \%$ of the mean duration of a short vowel), but the phonological grammar is presumably formed on the basis of categoricized data (see Ohala 1989; 1992; 1993). That is, whether the ambient data instantiates deletion or reduction is not a free parameter that language learning may manipulate; learners must build a phonological grammar off of their perceived phonetic data, and they may not second-guess their perception.

Following Bloomfield's description, it is clear that 1930's Nishnaabemwin at least approached the threshold for reinterpretation as deletion. Section 2.3 will review evidence that it had crossed the threshold.

\subsubsection{Extrapolated Phonologization}

The default expectation when a phonetic pattern becomes extreme is that the succeeding stage of the language will feature a categorical phonological version of the gradient phonetics. If severe reduction were phonologized as rhythmic deletion, the following generation would be expected to productively maintain a categorical version of the alternations illustrated in (1). This categorical derivation is shown in (3).

\begin{tabular}{|c|c|c|}
\hline 'If he kicks him' & 'I kick him' & 1930's (phonologized) \\
\hline /d $\Lambda$ JgI $\int k \Lambda w-a:-d$ & /nI-d $\Lambda \mathrm{ygI} \int \mathrm{k} \Lambda \mathrm{w}-\mathrm{a} / \mathrm{I}$ & UR \\
\hline$($ dıjgíf $)(k \Lambda w a ́: d)$ & 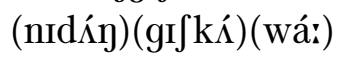 & Stress \\
\hline$($ d_ygíf $)\left(k \_w a ́ i d\right)$ & $\left(\mathrm{n} \_\mathrm{d} \hat{y} \mathrm{y}\right)\left(\mathrm{g} \int \mathrm{k} \hat{\Lambda}\right)($ wá: $)$ & Syncope \\
\hline d_ygíf)(k_wást) & . & Other rules \\
\hline [dygífkwárt] & [ndíggfkńwá:] & SR \\
\hline
\end{tabular}

However, if learners have difficulty with rhythmic syncope, veridical phonologization might never occur.

\subsection{Modern Nishnaabemwin (Post-1930's)}

Reports written after Bloomfield (1957) indicate that Nishnaabemwin had substantially changed. Rhodes (1985b:467) reports the rise of an "innovative" dialect that utilizes new prefixes and that has leveled out the alternations from 1930's 
Nishnaabemwin (see also Kaye 1974, Rhodes 1975, Piggott 1980 [1974], discussed in section 2.3). Recall from (1) that 'kick someone' alternated between

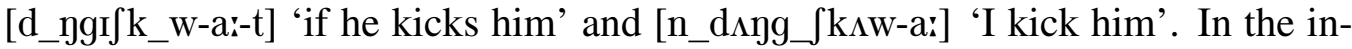
novative dialect, 'I kick him' is [ndo:-djgIfkw-a:], which has a novel prefix and vocalism for a prefixed form. Strikingly, with the innovation of [ndo:-dngi $\int \mathrm{kw}-\mathrm{a}$ :] 'I kick him', the paradigm has lost the classic rhythmic syncope alternations, since 'if he kicks him' is still [djgi $\int \mathrm{kw}-\mathrm{a}$ - $-\mathrm{t}$ ]. This combination of leveled paradigms with innovative prefixes is the "regular" inflectional pattern in the innovative dialect (Rhodes 1985b:466), as is robustly reflected in the dictionary published in the same year (Rhodes 1985a), a sampling of which is reproduced in (4). ${ }^{2}$

\begin{tabular}{|c|c|c|c|}
\hline ' (both) & 'I ...' (new) & 'I ...' (1930’s) & \\
\hline nsidpw-a:-t & ndo:-nsidpw-a: & n-nisd $v p w-a:$ & notice his taste \\
\hline dgonge:-t & ndo:-dgonge: & n-d $\operatorname{lgnig\varepsilon :}$ & mix things \\
\hline bzoge: $\int \mathrm{In}$ & 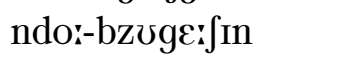 & n-bizge: $\int \mathrm{n}$ & stumble \\
\hline o:-t & ndo:-znıgto: & n-Zıjgito: & struggle \\
\hline tIgmingibn-a:-t & ndo:-gtigmingibn-a: & n-gotgomnıgbin-a: & roll him \\
\hline
\end{tabular}

The innovative prefixation strategy is slightly more complicated, as three prefix allomorphs have emerged (all three prefix allomorphs are legal on the words in (4), but only one is shown for brevity). In addition to ndo:-, first person may also be realized as ndI- or nd $\Lambda^{-}$. According to Rhodes (1985b:467), ndo:- and $n d_{\Lambda}$ - predominate in Odawa communities, while $n d_{I-}$ is favored in Eastern Ojibwe communities.

The adoption of a consistent vocalism in place of the 1930's alternations deviates from the extrapolated phonologization sketched in section 2.1.3. The origin of the consistent vocalism does not warrant further mention here, as it can be straightforwardly traced from the unprefixed allomorph used in the 1930's (see Bowers 2015). In contrast, at first blush the innovative prefixes seem to have no precedent from the 1930's, since the syncopated realization for the prefix $n{ }^{-}$is simply $n$-. The following section discusses the likely origin of the modern Nishnaabemwin prefix system.

\footnotetext{
${ }^{2}$ There is a further set of alternations, not discussed here, whose restructuring would also be fruitful to investigate. Namely, complementation can be realized by an ablaut process that targets the first vowel of the word ('initial change' in Algonquianist terminology, see Valentine 2001:155). The deletion of alternating short vowels removed the un-ablauted vowel from isolation forms, so those forms were no longer informative for which ablaut pattern to deploy. Rhodes (1996:4) observes that the ablaut pattern became dispreferred relative to a prefixation strategy. However, the ablaut pattern resisted change in relative clauses ('participle' forms in Algonquianist terminology).
} 


\subsubsection{Prefix Allomorph Origins}

The innovative prefix allomorphs were not created out of whole cloth, but most likely arose via reanalysis of words that historically began with short vowels, so that the former stem-initial material was parsed into the prefix. Example (5) shows a 1930's Nishnaabemwin derivation that motivated $n d_{\Lambda}$ - (recall from section 2.1.1 that [d] was inserted to break vowel hiatus across the prefix-stem boundary).

\begin{tabular}{|c|c|c|}
\hline 'I hang' & 'If he hangs' & 1930's \\
\hline /nI- $\operatorname{go:} \widehat{d_{3}}$ In/ & 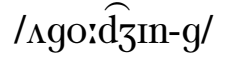 & UR \\
\hline $\mathrm{nI}[\mathrm{d}] \Lambda \mathrm{go:} \widehat{\mathrm{d}_{3} \mathrm{In}}$ & & Hiatus Resolution \\
\hline (nIdর́)(gó:)(đđđín) & 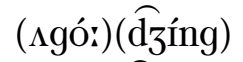 & Stress \\
\hline 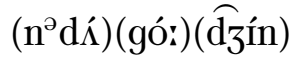 & $\left({ }^{\ominus}\right.$ gó: $)(\widehat{d}$ zíng) & Reduction \\
\hline 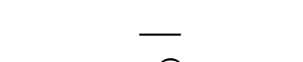 & 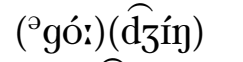 & Other rules \\
\hline •dńgó:dz̧ín] & 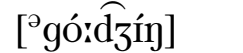 & SR \\
\hline
\end{tabular}

Because the stress algorithm "restarted" the iambic stress pattern after a long vowel, the person prefix only affected the footing of the stem-initial vowel in / $\cos d \mathrm{~d}_{3} \mathrm{Im} /$. This means that when the form had no person prefix, the stem-initial

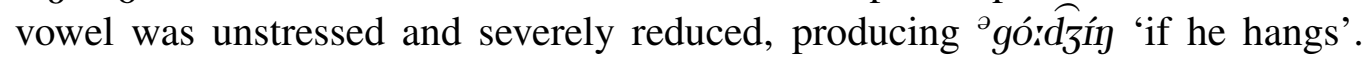
When a person prefix was attached, the stem initial vowel was stressed, as in $n^{\curvearrowright}$-dígo:ḑ̇ín.

From the perspective of a language learner, the segmentation of $n$ - given the unsegmented forms nd $\Lambda$ go: $\widehat{d}_{3} I n$ 'I hang' and go: $\widehat{d}_{3} I \eta$ 'if he hangs' could leave [d $\Lambda$ ] with no morphemic parse. In contrast, a historically incorrect parse of the prefix as $n d_{\Lambda}$ - leaves no unexplained material, as schematized in (6).

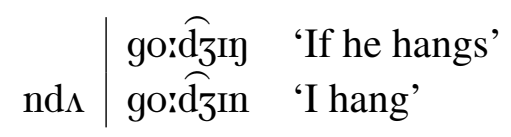

With this segmentation, the formerly stem-initial vowel has become part of the prefix, and the stem is now consonant-initial.

This process can be repeated for stems that began with other short vowels. The derivations of the 1930's Nishnaabemwin stem /ina:b d $_{3}$ to: / 'use something so' in (7) demonstrate how ndI- arose from forms like ${ }^{2}$ ná: $b^{\supset} \widehat{d}_{3}$ ítór-t 'if he uses it so' and $n^{\curvearrowright}$-díná: $b^{\curvearrowright}$ dु'ítós-n 'I use it so'. 
(7)

\begin{tabular}{|c|c|c|}
\hline 'I use it so' & 'If he uses it so' & 1930’s \\
\hline /nI-Ina:bs $\widehat{d}$ Ito:-n/ & 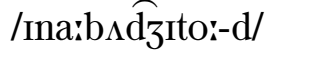 & UR \\
\hline $\mathrm{nI}[\mathrm{d}] \operatorname{ma}: \mathrm{b} \Lambda \widehat{\mathrm{d}}{ }_{3}$ Ito:n & - & Hiatus Resolution \\
\hline 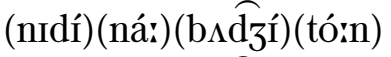 & 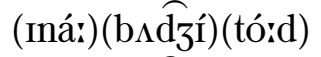 & Stress \\
\hline 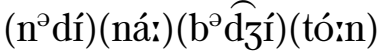 & 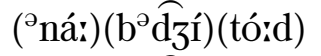 & Reduction \\
\hline - & 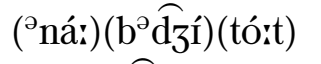 & Other rules \\
\hline 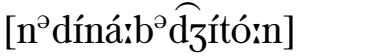 & [ ${ }^{\ominus}$ ná:b ${ }^{\ominus}$ dzító:t $]$ & SR \\
\hline
\end{tabular}

Aligning the words provides the first person prefix ndI--

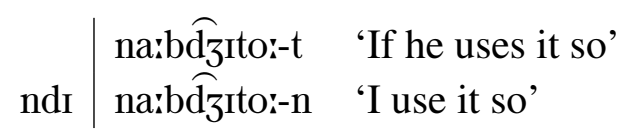

Words like 1930's Nishnaabemwin / $\widehat{\text { d }} 3$ E:pizi/ 'be lively' were the source for ndo:-. Consider first the 1930's Nishnaabemwin derivations in (9). Note that in a quirk common in Algonquian languages, [ซ] lengthened after a prefix.

\begin{tabular}{|c|c|c|}
\hline 'I am lively' & 'If he is lively' & 1930’s \\
\hline$/ \mathrm{nI}-\mho \widehat{\mathrm{d}} 3 \varepsilon: p I z \mathrm{I} /$ & 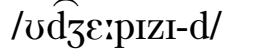 & UR \\
\hline 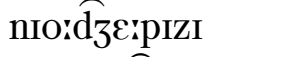 & - & [v] Lengthening \\
\hline nI[d]o: $\widehat{d} \bar{z} \varepsilon: p I z I$ & - & Hiatus Resolution \\
\hline nIdo: $\widehat{d}_{3} \varepsilon: p I z$ & - & Apocope \\
\hline 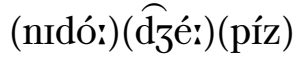 & 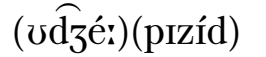 & Stress \\
\hline 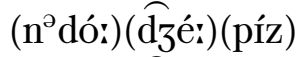 & $\left({ }^{\circ} \widehat{\mathrm{d}_{3}} \mathrm{é}^{\prime}\right)\left(\mathrm{p}^{\ni} \mathrm{zi} \mathrm{d}\right)$ & Reduction \\
\hline 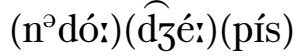 & $\left({ }^{\circ} \widehat{\mathrm{d}_{3}} \mathrm{é}_{\mathrm{i}}\right)\left(\mathrm{p}^{\curvearrowright} \mathrm{zít}\right)$ & Other rules \\
\hline [nº́dó:đZé:pís] & [ ${ }^{\circ} \widehat{d} z$ é:p $\left.{ }^{\partial} z i ́ t\right]$ & SR \\
\hline
\end{tabular}

Alignment of the two surface forms provides a plausible source for a first person prefix ndo:- and a stem $\widehat{d_{3}}$ E:pIzI 'be lively'.

$$
\text { ndo: } \mid \begin{array}{ll}
\widehat{\mathrm{d}_{3} \text { e:pzI-t }} & \text { 'If he is lively' } \\
\mathrm{d}_{3} \text { E:pIS } & \text { 'I am lively' }
\end{array}
$$

Note that while the recutting analysis evidently was adopted, it is obviously not the only imaginable analysis. Given a rhythmic syncope grammar, the pres-

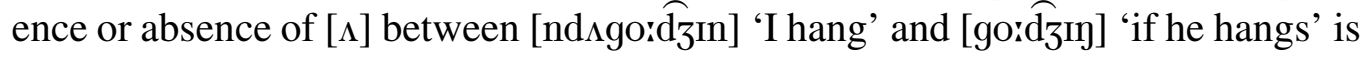
explainable as the result of the serial interaction of stress and syncope. Moreover, 
the limitation of this $[\Lambda]-\emptyset$ alternation to particular lexical items is usually taken to be evidence that the $[\Lambda]$ is part of the lexical representation of the stem, not the prefix. The prefix inventory would then consist of $n$ - and $n d$ - (see immediately below), with the former occurring before consonant-initial stems, and the latter occurring before vowel-initial stems.

Learners had strong evidence for simpler prefixes as well. Far and away the most frequent prefix allomorph $n$ - was segmentable off of CVV-initial words like /gaiskınひzひ/ 'whisper', whose derivations appear in (11).

\begin{tabular}{|c|c|c|}
\hline 'I whisper' & 'If he whispers' & 1930’s \\
\hline /nI-garskınひzซ/ & /gaiskınひzひ-d/ & UR \\
\hline nI-garsk $\Lambda$ n $\mho z_{Z}$ & - & Apocope \\
\hline (nIgá:s)(kıń̛z) & $($ gá:s)(kıń̛)(zúd) & Stress \\
\hline (n gá:s) $\left(k^{\curvearrowright}\right.$ núz) & (gá:s)(knú)(zưd) & Reduction \\
\hline (n gáis)(kº̛́s) & (gá:s)(kºứ)(zút) & Other rules \\
\hline [nº́ásk ${ }^{\ominus}$ ứs] & [gá:skªưzút] & SR \\
\hline
\end{tabular}

Aligning [ngaisknos] 'I whisper' and [ga:sknzzot] 'If he whispers' allows the segmentation of $n-$.

$$
\mathrm{n} \mid \begin{array}{ll}
\text { gaisknozo-t } & \text { 'If he whispers' } \\
\text { gaisknos } & \text { 'I whisper' }
\end{array}
$$

Finally, the allomorph nd- could be segmented from 1930's Nishnaabemwin words that began with long vowels, like $n^{\curvearrowright} d$-á:dárg né:fín 'I am snow-bound'.

\begin{tabular}{|c|c|c|}
\hline 'I am snow-bound' & 'If he is snow-bound' & 1930’s \\
\hline 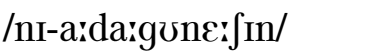 & 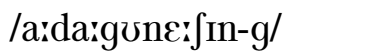 & UR \\
\hline 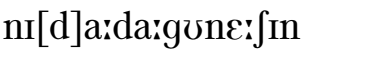 & - & Hiatus Resolution \\
\hline (nidá:)(dá:)(goné:)( (ín) & 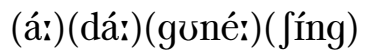 & Stress \\
\hline 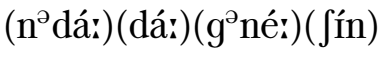 & (á:)(dá:)(gª́́:)(Jíng) & Reduction \\
\hline - & 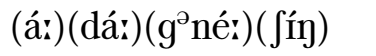 & Other rules \\
\hline$n^{\curvearrowright}$ dá:dá:g ${ }^{\curvearrowright}$ né:[ín] & 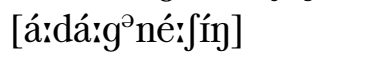 & SR \\
\hline
\end{tabular}

In (14) the segmentation producing nd- is illustrated.

$$
\text { nd } \mid \begin{array}{ll}
\operatorname{ardargne:} \int \mathrm{In} & \text { 'If he is snow-bound' } \\
\operatorname{ardargne:\int in} & \text { 'I am snow-bound' }
\end{array}
$$


Summing up, learners evidently took 1930's Nishnaabemwin surface forms as supporting five prefix allomorphs for first person. Of these five, nd $\Lambda^{-}$and ndo:emerged as practical default forms in Odawa communities. ${ }^{3}$

Setting aside further discussion until section 7, modern Nishnaabemwin has a straightforward description: prefixes ndo:-, nd $\Lambda^{-}, n_{I^{-}}, n^{-}$, and nd- compete to be attached to stems. Given the interchangeability reported by Rhodes (1985a; 1985b), some of the competition must be decided probabilistically, with nd $\Lambda^{-}$and ndo:- being the most likely allomorphs to be deployed in Odawa communities. Some categorical effects clearly also hold, since, for instance, *nd-gaisknzz is unreported. This is straightforwardly explained, since the word-initial clusters in such forms were unattested in 1930's Nishnaabemwin, and thus could be expected to be ruled out by undominated phonotactic constraints.

\subsection{Restructuring Coincided with Deletion Interpretation}

Thus far, we have seen that adult speakers of Nishnaabemwin in the 1930's had extreme phonetic reduction of unstressed vowels (section 2.1), that reduction was reinterpretable as deletion (section 2.1.2), and that Nishnaabemwin now contains innovative prefixes and leveled paradigms (section 2.2). This section reviews evidence that restructuring was initiated at the same time that severe reduction was documented, and that restructuring went hand in hand with the reinterpretation of reduction as deletion. Section 2.3.1 discusses evidence that restructuring may have begun slightly before the reinterpretation of reduction as deletion, while section 2.4 discusses claims that restructuring may not have been adopted by all members of the cohort.

The first reports after Bloomfield (1957) contain terse indications that a major change was underway in Nishnaabemwin. A remarkably precise date for the initiation of restructuring can be inferred from Piggott (1980 [1974]:2), who writes that "the elaborate inflectional system of Ojibwa [Nishnaabemwin] which is well attested in the grammar of older speakers has undergone (or, rather, is undergoing) considerable modification in the grammar of speakers who are in the mid-thirties and under". The changes Piggott mentioned most likely include the prefix reanalysis and stem leveling discussed above (Glyne Piggott p.c.). This is buttressed by the fact that Rhodes (1985b) and Valentine (1994; 2001) exclusively discuss

\footnotetext{
${ }^{3}$ Second person prefixes regularized in the same way, producing $g d_{\Lambda^{-}}, g d_{0^{-}-}, g \mathrm{~d}_{-}-, g_{-}$, and $g d-$. For third person, 1930's Nishnaabemwin $v^{-}$left behind $d_{\Lambda_{-}-}, d_{0^{-}-}$, and $d \mathrm{I}^{-}$, which mark third person noun possession in modern Nishnaabemwin. Third person inflection on verbs is typically not signaled with a prefix in modern Nishnaabemwin.
} 
the novel prefixation system plus leveling as the key morphological innovation in Nishnaabemwin.

The age of the leading edge of the cohort suggests that the 1930's Nishnaabemwin pattern began to be abandoned in the late 1930's. Piggott's (1980 [1974]) description describes field data from 1968-1974. Importantly, the speakers who were in their mid-thirties and younger between 1968 and 1974 were children during the period of extreme reduction documented by Bloomfield in 1938.

Where Piggott (1980 [1974]) suggests a concrete date for the initiation of restructuring, Rhodes $(1975 ; 1985 \mathrm{~b}$ inter alia) affirms that the prior generation had severe reduction, and that the restructuring cohort reinterpreted it as deletion. Rhodes (1975:130) notes that for older speakers, "deletion seems to be a [...] casual speech phenomenon", which echoes Bloomfield's description of a low level reduction process. Rhodes further reports that older speakers had an intuitive awareness of absent vowels, stating that "the vowels can be easily resupplied (with only some ambiguity of quality)" (ibid). This contrasts with younger speakers, for whom absent vowels are "totally abstract", since "they cannot resupply the [missing, DAB] vowels except by reference to appropriate allomorphs" (ibid). Such distinct types of awareness should match distinct linguistic characterizations, like the difference between a gradient phonetic process and a categorical one.

Somewhat later, Rhodes (1985b:464-466) provides concrete evidence that missing vowels are truly absent for younger speakers. Recall from section 2.1.2 that in 1930's Nishnaabemwin severely reduced vowels could still surface as short vocoids. In modern Nishnaabemwin, short vocoid segments do not correspond to the reduced vowels described by Bloomfield. That is, both modern [ $\left.n^{v} w \varepsilon^{v}\right]$ 'he speaks' and modern [a:n $\left.{ }^{\mho} \mathrm{wI}\right]$ 'despite' have the same vocoid, but the vocoid is innovative in [ ${ }^{\mho}{ }^{w}$ : $]$ 'he speaks' (cf. Western Ojibwe [mwe:] 'he speaks', Nichols 2015), while the vocoid corresponds to a historical vowel in [a: $\left.{ }^{\mho} \mathrm{wI}\right]$ 'despite' (cf. Western Ojibwe [a:n $\Lambda$ wI] 'despite', Nichols 2015).

Rhodes further shows that the presence and quality of excrescent vocoids can be predicted by the identity of flanking consonants. This is standardly interpreted as evidence that the vocoids are the result of phonetic interpolation between $\mathrm{C}-\mathrm{C}$ transitions. Interpolation between consonants presupposes that the consonants are adjacent prior to phonetic implementation, even if they historically were separated by a vowel. The neutralization of the distinction between originally adjacent consonants and formerly separated consonants provides further evidence that in modern Nishnaabemwin, etymological vowels have been categorically removed. On a similar note, Rhodes (1985b:468-469) and Valentine (2001:73-89) enumerate several neutralizations in consonant clusters that are derived by reduction-cum- 
syncope, which presupposes that formerly separated consonants are now adjacent phonologically. Importantly, these data only diagnose categorical absence, but leave unresolved the key question of whether the absent vowels are removed by synchronic rhythmic syncope, or whether they were lost outright from underlying representations (see section 7).

Hence, the contemporary reports suggest that the recent development of Nishnaabemwin is divided into two stages: a severe reduction stage in the 1930's, and a subsequent restructured stage. Furthermore, the onset of restructuring coincided with the interpretation of reduction as deletion.

\subsubsection{Possible Early Restructuring}

Bloomfield $(1957: 5,24)$ occasionally records some forms that presage the imminent restructuring, as in ndo:-bgskta:n 'I hear it distinctly', where n-bugkita:n is the expected conservative form (Rhodes 1985b:467). These forms suggest several possibilities, including that Bloomfield's consultant was updating his grammar on the basis of a re-analysis of adult speech (Rhodes 1985b:468), or as a reviewer suggests, that restructuring had already taken place and that Bloomfield's report is in fact an idealized reconstruction, rather than an accurate representation of his consultant's speech. While we cannot rule out either of these possibilities, the first would require a more sophisticated model of grammar construction than we are inclined to argue for here, while the second alleges that Bloomfield extensively falsified the data, despite going so far as to explicitly admit to reconstructing only a handful of forms (Bloomfield 1957:6). ${ }^{4}$

An alternative is that these prescient restructured forms were borrowed from Potawatomi, a very closely related language. Potawatomi developed severe reduction shortly before Nishnaabemwin, and is in fact widely credited with having introduced reduction to Nishnaabemwin, as Potawatomi speakers fled the United States and settled in southern Nishnaabemwin speaking communities (Rhodes 1985a:x, Valentine 1994:151). Importantly, Potawatomi also was already undergoing a similar restructuring to Nishnaabemwin, as ndo:- was becoming a prefix in its own right (Hockett 1939:28-29, 1948:5). ${ }^{5}$

\footnotetext{
${ }^{4}$ Given Bloomfield's practice of keeping 'the reader out of the kitchen', Bloomfield could have provided few restructuring examples for brevity. It does not appear that this is the case. Parsing the roughly 10,000 words recorded by Bloomfield with a finite state parser (Bowers et al 2017) revealed only three more words formed with the innovative prefixation strategy beyond the three acknowledged by Bloomfield.

${ }^{5}$ Lockwood (2017) indicates that the Potawatomi analog of Nishnaabemwin nd $\Lambda^{-}$and ndI-
} 
Bloomfield's consultant lived on Walpole Island, a southern community, and thus would likely have been exposed to a substantial amount of Potawatomi. Bloomfield may therefore have simply recorded the sporadic use of a prefixation strategy that had been borrowed. Under this account, Bloomfield's consultant reduced, but did not delete, unstressed vowels, while sometimes deploying forms borrowed from Potawatomi. Regardless of which explanation ultimately proves correct, the stark difference between the original severe reduction pattern (with at most a smattering of restructured forms) and the later language (with prolific use of restructured forms) points to a major reanalysis on the part of learners.

\subsection{Possible Heterogeneity in Restructuring Cohort}

While the early reports established that restructuring emerged with the reinterpretation of reduction as deletion, later work indicates it may not have been the only analysis. Valentine (1994:150) stops short of claiming that all younger speakers restructured the phonology, affirming only that restructuring has occurred "at least for some speakers". Sometime later, Valentine (2001:65-67) substantiates the implied restriction by limiting the restructuring to younger and/or less proficient speakers. The limitation to younger speakers is certainly consistent with the reports from the 1970's, though the original cohort from the 1970's would have been approaching or over 60 years old in 2001, and thus is unlikely to qualify as young. Note, however, that even if Valentine is referring to a still-younger cohort, it is unlikely that they would have been much younger than 30 years old, since intergenerational transmission in even the most robust Nishnaabemwin-speaking communities ceased in the 1960's. ${ }^{6}$

More importantly, Valentine (2001:66-7, citing unpublished pedagogical materials by Mary Ann Corbiere) indicates that restructuring is limited to less proficient or even attrited speakers, and that highly proficient speakers continue to use the conservative 1930's system. Such highly proficient conservative speakers may even include members of the restructuring cohort (Rand Valentine, p.c.). However, Valentine (2001:66) acknowledges that there has been no systematic study of how widespread innovative prefixes and levelled paradigms are in modern Nishnaabemwin.

eventually won out over ndo:-

${ }^{6}$ Though Valentine (2001:68-70) provides a text narrated by a 10-year-old character, the author was in fact an adult (Rand Valentine, p.c.). The text should not be taken as evidence of the usage of a speaker born around 1991. 
The current descriptive literature thus does not provide a clear picture of learners' response to perceived rhythmic syncope. While the earliest reports suggest a uniform rejection of the rhythmic syncope alternations, sufficiently expert speakers may prefer the conservative pattern, or perhaps even exclusively use it. Whichever scenario is actually attested has significant potential implications for the learnability of rhythmic syncope. If all learners failed to acquire the original rhythmic syncope pattern, a rhythmic syncope grammar may be highly dispreferred or perhaps even impossible for learners. On the other hand, if at least some learners succeed in acquiring rhythmic syncope, a rhythmic syncope grammar must be attainable at least some of the time. If those conservative speakers are generally non-attrited, whether a rhythmic syncope grammar is acquired may depend on the amount of exposure to the pattern.

Looking forward, the surveys in this study seek to address these questions. The first two surveys measure speakers' intuitions regarding prefix choice (innovative versus conservative) on stems that either did not (survey 1), or did (survey 2) alternate in 1930's Nishnaabemwin. The key concern is whether some or all speakers will show a preference for conservative 1930's patterns, and thus demonstrate that rhythmic syncope is acquirable. The third survey directly tests the theory that the restructuring was due to insufficient exposure to 1930's forms by measuring the accuracy with which speakers differentiate 1930's forms from foils. Moreover, the participant sample deliberately included a range of proficiencies within the target cohort, so that any effect of proficiency on conservativism could be measured.

\subsection{Further Desiderata}

The descriptive literature is incomplete in other respects as well. Rhodes (1985b:466) claims that new prefixes did not spread across the entire lexicon, but that the new prefixes are limited to "exactly" stems that had vowel-zero alternations after the first stem consonant in 1930's Nishnaabemwin. That is, words that had no leftedge alternations under prefixation in 1930's Nishnaabemwin, as in [n-ga:sknus] 'I whisper' (unprefixed form: [gaisknzzo-t] 'if he whispers'), or words where the only alternation could be attributed to prefix allomorphy, as in [nd- $\Lambda$ go: $\widehat{d}_{3}$ In] 'I hang' (unprefixed form: [go: $\left.\widehat{d}_{3} \operatorname{In}\right]$ ), reportedly take only etymologically correct prefixes. In contrast, words that alternated after the first stem consonant under prefixation, as in [n-miskwi:wnike:] 'I have a bleeding arm' (unprefixed form: [mskwi:wnike:] 'he has a bleeding arm'), do take the innovative prefixation pattern, as in [nd $\Lambda$-mskwi:wnrke:] 'I have a bleeding arm' (Rhodes 1985b:467). This pattern of prefixation is fairly robust in Rhodes (1985a), where non-alternating 
stems often are not listed with innovative prefixes. However, the force of the claim that new prefixes are limited to historically alternating stems is vitiated when Rhodes (1985b:467) mentions that for "these same speakers" who have innovated modern Nishnaabemwin, novel prefixation has spread to many formerly non-alternating words, as seen in modern Nishnaabemwin za:msini: 'he overeats' and nd $\Lambda$-za:msini: 'I overeat' (1930's Nishnaabemwin prefixed form [nd-o:za:msini:] 'I overeat').

Finally, according to the description of the data in his dictionary (Rhodes 1985a:xx), new prefixes may appear on verbs, but not nouns. The validity of this is unclear, as Valentine (1994:146-147) adduces nouns with innovative prefixes. Furthermore, there were editorial considerations that may have resulted in the suppression of innovative prefixes on nouns in Rhodes' dictionary (Richard Rhodes, p.c.).

In sum, within the broader goal of measuring the degree of innovation after incipient rhythmic deletion, this study seeks to address the following empirical goals:

- Establish whether innovative or conservative prefixation is preferred on historically non-alternating words (survey 1).

- Assess the degree to which speakers prefer innovative prefixation (with concomitant leveling) over conservative prefixation on historically alternating words (survey 2).

- Assess the degree of exposure to 1930's Nishnaabemwin forms by testing the ability to differentiate 1930's Nishnaabemwin forms from foils (survey $3)$.

- Probe whether proficiency, age, lexical category (noun versus verb), or word familiarity influence the use of innovative prefixation or conservative prefixation (all surveys).

Foreshadowing the main results, modern Nishnaabemwin was uniformly adopted by participants of all ages and proficiencies, while innovative prefixation occurred whether or not stems historically alternated and whether or not stems were nouns or verbs. Furthermore, in the final survey participants reliably distinguished historical forms from foils. These results suggest that despite substantial exposure to the historical deletion pattern, the cohort in question uniformly converged on a changed language. 


\section{General Methods}

20 native speakers (12 female, 8 male) of Nishnaabemwin between the ages of 61 and 87 (mean: 71.6 years, standard deviation: 7.3 years) participated in the study. Participants grew up speaking the Odawa variety of Nishnaabemwin on Manitoulin Island (15) or Walpole Island (5). The participant pool included several highly esteemed translators and language instructors, but also included speakers who were not professionally involved in the language. ${ }^{7}$

Each participant completed three surveys, though one potential participant (not included in the results) only completed part of the first survey before withdrawing. Each survey consisted of at least 30 words, and could include either nouns or verbs. Words were drawn randomly from Corbiere and Valentine (2016). Each participant was surveyed using a different set of randomly drawn words in order to ensure a broad swath of the lexicon was sampled. This broad sample of the lexicon permits more confident claims about the prevalence of the patterns across the lexicon than if only a few words were sampled. To allow direct comparison of participants to each other, surveys also included a core set of words that were shown to all participants. In all, 1,441 words were sampled, of which 1,030 were sampled once, 376 were sampled between two and ten times, and 35 were sampled more than ten times. In total, 969 words were recognized by at least one participant.

Stimuli were presented using a widely used roman orthography, with instructions in English. Participants were instructed that their day-to-day speech, as opposed to a more formal register, was of interest. Surveys were conducted in the homes of participants. Participants were given \$50 CAD for their time.

In the first survey, participants rated and made forced-choice judgements of all possible prefix allomorphs on historically non-alternating stems. In the second survey, participants made a forced-choice judgement between 1930's Nishnaabemwin alternating prefixed forms and modern Nishnaabemwin leveled prefixed forms. In the third survey, participants made a forced-choice judgement between 1930's Nishnaabemwin alternating prefixed forms and unattested foils. The full set of surveys typically took between 90 and 120 minutes to complete.

Well-formedness ratings and forced-choice preferences are, like all methodologies, imperfect windows to speakers' grammars. In a case of language change

\footnotetext{
${ }^{7}$ Though Nishnaabemwin is endangered and precise counts of the number of native speakers are not available, this sample did not contain all or even close to most living speakers of Nishnaabemwin. As a result, statistical models will be used to quantify the certainty that the results reflect true characteristics of the general population.
} 
with multiple competing variants, the chief concern is to demarcate all possibilities. By directly querying the relevant variants, this study addresses the question head-on, and reduces the chance that a minority variant will not be measured simply because it is improbable rather than impossible. Of course, suggesting rare forms can make participants overstate how much they prefer them (see Albright and Hayes 2003 section 4.3.4). This means that the regularization found in this study is likely to be even stronger than our current measurements indicate. Collecting a corpus or eliciting speaker productions without suggesting forms would help provide a fuller picture.

\subsection{Speaker Proficiency and Word Familiarity}

In this study, it is especially important to assess the effects of speaker proficiency and word frequency. Speaker proficiency must be tracked so that (a) we can ensure that the sample of participants was not mistakenly filled with heavily attrited individuals, and (b) we can check if proficiency is significantly correlated with a speakers' use of conservative forms. Word frequency is a perennial variable of interest in both synchronic and diachronic studies (see for instance Hay et al 2015, Bybee 2001), and in this study we would expect highly frequent words to correlate with a higher degree of conservatism. Unfortunately, standardized proficiency tests and large text databases for calculating frequency do not exist for Nishnaabemwin. However, the design of the experiment allows vocabulary size and word familiarity to be estimated. We use these as proxies for proficiency and frequency.

Word familiarity was calculated by dividing the number of participants who recognized a word by the total number of participants who were shown that word. Because words were drawn randomly in order to sample more of the lexicon, an individual word was typically shown only to at most a handful of participants. To avoid claiming that a word is universally recognized when it had been shown to few participants, familiarity estimates were Laplace smoothed with a constant value of 2 . Thus, if a word had only been shown to and recognized by a single participant, we conservatively estimate that one third of speakers would recognize it, while a word that was shown to and recognized by twenty participants is estimated to be recognized by $\frac{20}{20+2}=91 \%$ of speakers. ${ }^{8}$

\footnotetext{
${ }^{8} \mathrm{~A}$ reviewer helpfully suggests that familiarity scores be log-tranformed in the analyses below. This results in a slightly worse fit to the data. Untransformed familiarity values will be used instead.
} 
To measure speaker proficiency, the percentage of words recognized by each speaker across all surveys was calculated. On average, speakers recognized $70.8 \%$ of words (standard deviation 13.7\%). This rate of vocabulary recognition is comparable to that of English-speaking adults (Brysbaert et al 2016). ${ }^{9}$ Note that participant age is not correlated with proficiency $\left(r^{2}=0.002\right)$, although the correlation does improve substantially if the two participants over 80 years old are excluded $\left(r^{2}=0.169\right)$.

\section{Survey 1: Prefix Distribution}

This first survey assesses the distribution of prefix allomorphs (see first bullet in section 2.5). The proliferation of innovative prefix allomorphs, along with the concomitant leveling of paradigmatic alternations, is a principal aspect of restructuring. This survey looks at historically non-alternating words in order to examine prefix allomorphs apart from alternations. The prevalence of leveled paradigms in place of alternations will be assessed in section 5 .

The narrow focus on prefix distribution helps illuminate the durability of rhythmic syncope patterns across generations, and by extension, the acquirability of a rhythmic syncope grammar. Any points of similarity between the stages of Nishnaabemwin could suggest that modern Nishnaabemwin retains a rhythmic syncope grammar. Conversely, if modern Nishnaabemwin departs from 1930's Nishnaabemwin, it is presumably because language learners disregarded the original distribution and overlaid a new pattern over it. Hence, whether restructured prefixes proliferated or the conservative prefix distribution endures can reveal whether prefix boundaries were misparsed or if the phonological explanation for apparent prefix allomorphy was adopted (see section 2.2.1).

The prior descriptive literature inconclusively suggests that historically nonalternating words retain the conservative 1930's distribution of prefix allomorphs (see section 2.5). Consequently, our null hypothesis is that for a historically nonalternating word, the historical prefix allomorph for the word will be preferred to the innovative prefix allomorphs (nd $\Lambda_{-}$and ndo:-). The alternative hypothe-

\footnotetext{
${ }^{9}$ Because participants were shown different words (due to the random draw), raw recognition percentage could be an inaccurate measure of proficiency. An alternative measure weights proficiency by the familiarity score of the words that they did and did not recognize. As it turns out, raw recognition percentage and familiarity-weighted proficiency are very highly correlated in our data $\left(r^{2}=0.912\right)$. For ease of interpretation, raw recognition percentage will be used in plots and models.
} 
sis is that innovative prefix allomorphs will be preferred to the historical prefix allomorph.

To test these hypotheses, the survey used the following design. Speakers evaluated all possible first person prefix allomorphs on stems that for present purposes were non-alternating in 1930's Nishnaabemwin, because they contain a long vowel after the first consonant. ${ }^{10}$ That is, for a word like gassknzzv- $t$ ' if

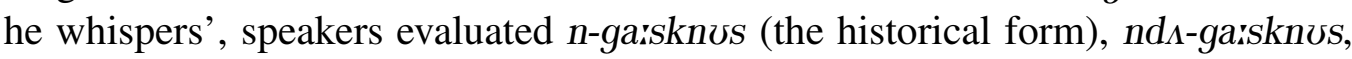
ndo:-ga:sknus, and ndI-gaisknos as ways to say 'I whisper'. For words that begin with a long vowel, the historical nd- allomorph was also evaluated, so that for a:d In 'be stranded', participants additionally evaluated nd-ard In 'I am stranded'. The nd-allomorph was not presented for the other words in the survey, because stimuli were constrained to be phonotactically legal, and the concatenation of ndto a $\mathrm{C}$-initial word would produce an unattested word-initial [ndC] cluster.

For each word, participants made a forced-choice judgement on which of the possible prefixed forms they were most likely to say, and rated each prefixed form on a 7-point Likert scale. If a speaker did not recognize a word, they were not asked to evaluate prefixed forms of it. The order in which the options were arranged on the screen varied randomly between trials. Participants evaluated words from the five classes that produced the distinct prefix allomorphs. Word class varied randomly between trials. The types of forms that participants evaluated are summarized in (15), where the bolded diagonal marks the historical prefix.

\begin{tabular}{|c|c|c|c|c|c|}
\hline & $\mathrm{C}$ & ${ }_{\Lambda} \mathrm{C}$ & $\mho \mathrm{C}$ & $\mathrm{IC}$ & VV \\
\hline \multirow{6}{*}{$\begin{array}{l}\text { n- } \\
\text { nd } \Lambda^{-} \\
\text {ndo:- } \\
\text { ndI- } \\
\text { nd- }\end{array}$} & n-gaisknus & n-go: $\widehat{d}$ In & n- $\widehat{d_{3}}$ E:pIs & n-na:b $\widehat{d}$ IIto:-n & n-a:dfin \\
\hline & nd $\Lambda$-garsknひs & nd $\Lambda-g o: \widehat{d}_{3} I n$ & nd $\Lambda-\widehat{d_{3}} \varepsilon: p I S$ & 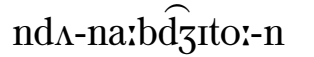 & $\operatorname{nd} \Lambda$-a:dfin \\
\hline & ndo:-ga:sknus & ndo:-go: $\widehat{d} 3$ In & 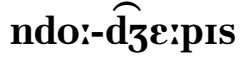 & ndo:-na:bd్ $\widehat{d}_{3}$ to:-n & ndo:-a:d $\int \mathrm{m}$ \\
\hline & ndI-ga:sknos & ndI-go: $\widehat{d}_{3}$ In & ndI- $\widehat{d_{3} \varepsilon: p I S}$ & 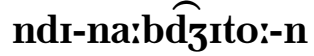 & ndI-a:dfin \\
\hline & - & - & - & - & 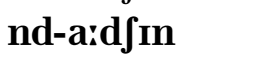 \\
\hline & 'I whisper' & 'I hang' & 'I am smart' & 'I use it so' & 'I am stranded' \\
\hline
\end{tabular}

To allow direct comparison of responses on a set of high-familiarity items, all speakers were presented with two words in each category that the author consid-

\footnotetext{
${ }^{10}$ Strictly speaking, many of the words in the survey did contain stem-internal alternation in 1930's Nishnaabemwin, but it was attributable to the choice of prefix allomorph. For instance, the word da:ba:n 'car' was historically vda:ba:n and in 1930's Nishnaabemwin the prefixed form was n-[d]o:da:ba:n 'my car'. Though the 1930's alternation between da:ba:n 'car' and n-[d]orda:ba:n 'my car' strictly speaking involved stem-internal material, because the prefixed form could be parsed as ndo:-da:ba:n, it counts as a non-alternating word for present purposes (see section 2.2.1).
} 
ered likely to be known by all participants. All remaining words were randomly selected. The survey ended once participants evaluated 6 words from each category, for a total of 30 evaluated words. Two participants did not complete all items. In total, 2,426 ratings of individual prefixed forms and 578 forced choice selections of the best prefixed form of a word were collected.

\subsection{Prefix Survey Results}

The prefix survey results strongly indicate that $n d_{\Lambda}{ }^{-}$and ndo:- are default allomorphs in modern Nishnaabemwin. The results also indicate that historical forms have not been entirely supplanted by default forms. To see the inter-weaving of historical attestation with regularization, consider the data in (16), which summarizes the results of the forced-choice component of the survey. Each cell contains the percentage of times a prefix was selected for a category (column). The bolded diagonal marks historical prefixes.

\begin{tabular}{lrrrrrr} 
& $\mathrm{C}$ & ${ }_{\Lambda} \mathrm{C}$ & $\mho \mathrm{C}$ & $\mathrm{IC}$ & $\mathrm{VV}$ & row mean \\
\hline $\mathrm{n}^{-}$ & $\mathbf{2 7}$ & 8 & 15 & 8 & 3 & 12.2 \\
nd $^{-}-$ & 33 & $\mathbf{4 9}$ & 16 & 29 & 34 & 32.2 \\
ndo:- $^{-}$ & 23 & 25 & $\mathbf{5 3}$ & 21 & 32 & 30.8 \\
ndI- & 17 & 17 & 15 & $\mathbf{4 2}$ & 4 & 19.0 \\
nd- & - & - & - & - & $\mathbf{2 7}$ & 27
\end{tabular}

Recall that Rhodes (1985b) and Valentine (2001) raise the possibility that speakers are conservative on non-alternating words and will consistently select the historical prefixed form. The effect of historical attestation can be most clearly seen by reading across the rows, where each prefix stands the best chance of being selected on its historical host. That is, the bolded cell is the largest in each row.

Despite this boost, the historical prefixes are not the clear favorites. Within each class of stem (columns in 16), the bolded historical form is the most commonly selected form only for the recut allomorphs (nd $\Lambda^{-}$, ndo:-, ndI-), and only ndo:- is selected more than $50 \%$ of the time. That is, the bolded cell is not categorically selected; it is in fact rarely the majority of its column, and it does not even consistently garner a plurality.

Instead of a conservative system, the forced-choice responses point to strong regularization, as at least one of $n d_{\Lambda}$ - or ndo:- is one of the top two prefix allomorphs in every column, and in three out of the five stem categories $(\Lambda \mathrm{C}, \mho \mathrm{C}$, 
VV), both $n d \Lambda^{-}$and ndo:- are the top two prefix allomorphs. Furthermore, nd $\Lambda^{-}$ and ndo:- together make up $74 \%$ to $50 \%$ of selected forms in any category.

Recall that Valentine (2001) indicates that more skilled Nishnaabemwin speakers use conservative 1930's prefixation. The measure of speaker proficiency (percentage of items recognized in all surveys) is not correlated with the rate at which speakers select historical forms $\left(r^{2}=0.006\right)$, as shown in the left panel of Figure 1. Perhaps more importantly, speakers generally select historical forms only around $40 \%$ of the time, while only 5 speakers select the historical form $50 \%$ or more of the time, and only one speaker selects historical forms over $75 \%$ of the time. Contrary to prior suggestions, participants uniformly do not employ 1930's Nishnaabemwin prefix allomorphy.

This is not to say that more proficient speakers are insensitive to historical attestation. The rating data (right panel of Figure 1) shows that more proficient speakers give modestly higher ratings to historical forms than less proficient speakers do.

\subsubsection{Statistical Methods and Model Construction Parameters}

The surveys in this study are oriented towards confirming whether the target cohort prefers conservative forms over innovative forms (surveys 1 and 2) or foil forms (survey 3), and finding factors that influence this preference. Note that the models discussed here are not models of phonological competence, as our goal is to descriptively track the retention of conservative features.

Given the descriptive nature of this study, an appropriate statistical method is to compare an array of hypotheses and gauge the relative strength of predictors within them (see Symonds and Moussalli 2011 for an accessible introduction to this approach to statistical modeling). A major difference between this approach and traditional null hypothesis testing is that it allows comparison of models whose predictors are not in a superset-subset relation, using Akaike's Information Criterion (AIC, where lower scores reflect better fit). When applicable, we also carry out null hypothesis tests and report $p$-values from the anova() function in $\mathrm{R}$ ( $\mathrm{R}$ Core Team 2016). When $\Delta \mathrm{AIC}$ scores and $p$-values diverge in whether a model is supported, we adopt the recommendation of the $p$-values. ${ }^{11}$

\footnotetext{
${ }^{11} \mathrm{AIC}$ scores and $p$-values measure different properties, as the AIC weights model complexity against the Kullback-Leibler distance between the model predictions and the observed data, while $p$-values state the probability that the observed effect for an included predictor would be obtained by sampling error. We rely on $p$-values because of their general familiarity and the more constrained nature of their comparanda (models where the predictors are in a subset-superset re-
} 

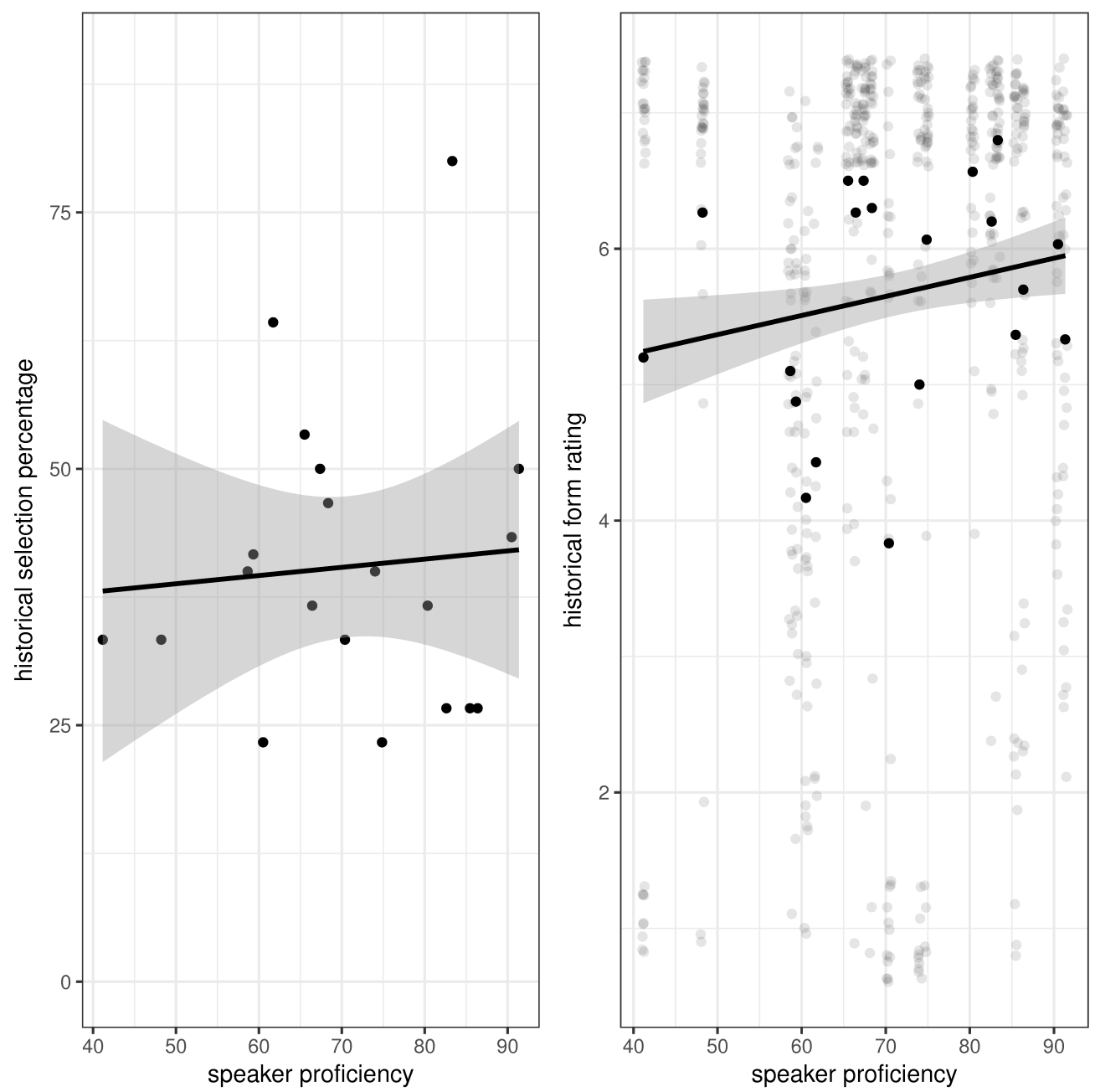

Figure 1: Plots of prefix survey results. Left panel: speaker-by-speaker plot of percentage of historical forms selected by proficiency score. Right panel: speakerby-speaker plot of rating given to historical forms by proficiency score. Dark dots indicate speaker means, light dots show raw ratings (jittered). 
Linear mixed effects models were fitted to the rating variable using the $\operatorname{lmer}()$ function from the package lme4 (Bates et al 2015) in R (R Core Team 2016). All models of the rating data contain random slopes for prefix allomorph by speaker. Models could also include prefix allomorph, whether an allomorph was historically attested on the stem in question, and interactions of participant age, participant proficiency or word familiarity with historical attestation. ${ }^{12}$ Including historical attestation as a predictor reflects the possibility that historical prefix allomorphs will receive higher ratings than innovative allomorphs. The interactions of historical attestation with age, proficiency and familiarity reflect the possibility that the historical form may recieve higher ratings on familiar words or from older or more proficient participants. To avoid scaling problems, speaker proficiency, speaker age, and word familiarity values were centered and rescaled.

\subsubsection{Hypothesis Testing and Model Selection}

Models including different configurations of fixed effects were compared using AIC scores and, for nested models, the likelihood ratio test via the anova() function in R. A truly null model with no fixed effects and a more plausible null model that includes historical attestation as a predictor were compared against models that also include fixed effects for whether the prefix allomorph is $n d_{\Lambda}-$ or $n d^{\prime} \mathbf{x}^{-}$Both null hypotheses can be rejected, as including whether the form is prefixed with nd $\Lambda^{-}$or ndor-significantly improves fit with respect to the truly null model $(p<0.001, \Delta \mathrm{AIC}=11.947)$ and with respect to the historical model $(p<0.001$, $\triangle \mathrm{AIC}=18.137)$.

The comparisons above merely show that our sample contains enough data from restructured speakers that modern default allomorphs are significantly correlated with ratings. As discussed in section 2.4, a more nuanced perspective might expect historical forms to receive improved ratings on widely familiar words, or from highly proficient or older speakers. Models with all combinations of these factors were fitted to the rating data. The best model according to AIC includes prefix allomorph, historical attestation, and its interaction with word familiarity and participant proficiency. The best model outperforms competing models that include only historical attestation $(p<0.001, \Delta \mathrm{AIC}=35.4)$, only prefix allomorph $(p<0.001, \Delta \mathrm{AIC}=80.2)$, the interaction between historical attestation

lation). In practice, this means that models may be supported if they do not have a large overall improvement in fit, but the effects of included predictors are unlikely to be due to sampling error.

${ }^{12}$ Lexical category was a potential predictor mentioned in section 2.5. Nouns and verbs behaved identically, and will not be further discussed. 
and speaker proficiency $(p<0.001, \Delta \mathrm{AIC}=23.1)$, or the interaction between historical attestation and word familiarity $(p=0.012, \Delta \mathrm{AIC}=-0.3)$. This supports the hypothesis that some speakers are more conservative than others, but does not conclusively rule out the hypothesis that these conservative speakers maintain the conservative 1930's pattern over the innovative pattern. We distinguish between these possibilities in the next section.

\subsubsection{Model Criticism}

In (17) the fixed effects of the maximal model of the data are shown. Predictors that are not present in the best model are italicized in (17), but are displayed in order to facilitate comparison between surveys. Examination of the estimates for the fixed effects emphasizes that innovative prefixation in modern Nishnaabemwin is thoroughly preferred, because effects favoring conservative prefixation are swamped by effects indicating prefix regularization. Four prefixes are shown in (17), the fifth, $n-$, is the reference level included in the intercept.

$\begin{array}{lrrr} & \text { Estimate } & \text { Std. Error } & \mathrm{t} \text { value } \\ \text { (Intercept) } & 4.20441 & 0.30002 & 14.014 \\ \text { historical } & 0.58740 & 0.09727 & 6.039 \\ \text { nd- } & 0.41458 & 0.38069 & 1.089 \\ \text { nd } \Lambda^{-} & 1.41182 & 0.26511 & 5.325 \\ \text { ndI- } & 0.39661 & 0.22952 & 1.728 \\ \text { ndo:- } & 1.62259 & 0.30751 & 5.277 \\ \text { proficiency(z-scored) } & 0.36704 & 0.14480 & 2.535 \\ \text { familiar(z-scored) } & -0.25793 & 0.04588 & -5.622 \\ \text { age(z-scored) } & 0.27938 & 0.14540 & 1.921 \\ \text { historical:proficiency } & 0.18881 & 0.08867 & 2.129 \\ \text { historical:familiar } & 0.40207 & 0.09592 & 4.192 \\ \text { historical:age } & 0.01290 & 0.08972 & 0.144\end{array}$

As in the forced choice data, the rating data clearly shows that $n d_{\Lambda}$ - and $n d o$ :- $^{-}$ are generally favored, as they are rated 1.4 and 1.6 points higher than the intercept value (n-). The remaining allomorphs have smaller, non-significant effects (absolute t-values greater than 2 indicate reliable effects). The non-default allomorphs $n-, n d-$ or $n d_{I-}$ only approximate the high ratings of $n d_{\Lambda-}$ or $n d o^{-}$- if they are the historical allomorph, the speaker is highly proficient, and the word is widely familiar. 
To be specific, the model estimates that non-default prefixes on their historical host words are rated 0.4 to 1.6 points lower than $n d_{\Lambda}$ - and ndo:-, all else being equal. In order to gain even an additional 0.4 points, the effects of proficiency $(\hat{\beta}=0.37)$ and familiarity $(\hat{\beta}=-0.26)$, and their interactions with historical attestation ( $\hat{\beta}=0.19$ and 0.40 , respectively) must be included. ${ }^{13}$ Only if a word is one standard deviation more familiar than average and a speaker is one standard deviation more proficient than average do the interaction terms contribute approximately 0.4 rating points. While highly proficient speakers clearly are more sensitive to historical attestation, they do not routinely prefer historical forms. Rather, the historical form is at best roughly equally favored to the modern regularized forms.

\subsubsection{Local Discussion}

To briefly summarize, the central question is how thoroughly did the restructuring cohort supplant the rhythmic syncope patterns. Previous literature tentatively suggests that prefix regularization has not applied to non-alternating words, and that some speakers resisted the change. The results of this survey suggest that $n d_{\Lambda}$ - and ndo:- are dominant for all speakers of modern Nishnaabemwin, even for words that did not have clear stem-internal alternations in 1930's Nishnaabemwin.

\section{Survey 2: Alternation vs Leveling}

The second survey examines innovative prefixation on historically alternating stems (second bullet point in 2.5), thus complementing the first survey, which examined only historically non-alternating stems. In a forced-choice task, participants were asked to choose whether they preferred a leveled prefixed form (ndo'-mkızIn 'my shoe') or a conservative form (n-makzIn 'my shoe'). Words in this survey historically began with a CVC sequence, and thus had unambiguous stem-internal alternations in 1930's Nishnaabemwin.

As before, the null hypothesis in this survey is that modern Nishnaabemwin maintains the conservative 1930's distribution if not for all speakers, then at least

\footnotetext{
${ }^{13}$ The negative coefficient for word familiarity may be surprising. It is negative because speakers rated ahistorical forms lower on more familiar words. In effect, they made a clearer distinction between historical forms and ahistorical forms on familiar words. Even after adjusting the predicted rating downwards for innovative applications of $n d_{\Lambda}$ - or ndo:- on widely familiar words, there is still a large gulf between the predicted values of the non-default allomorphs and the innovative defaults.
} 
for the highly proficient ones. The alternative hypothesis is that this cohort prefers innovative prefixation.

Rhodes' (1985b) report leaves open the possibility that innovative prefixation applies to all formerly alternating stems at the same rate, without distinguishing between the number of alternating vowels. The survey tested this possibility by sorting words according to the number of stem-internal vowel-zero alternations present in 1930's Nishnaabemwin, or equivalently, the number of vowel-zero mismatches between the innovative prefixed form and the conservative prefixed form. The lexicon was partitioned by the number of vowel-zero disparities between the conservative $n$ - form and the innovative ndo:-, with the maximum number of alternating vowels being five. This is schematized in (18) for words with one to three alternating vowels.

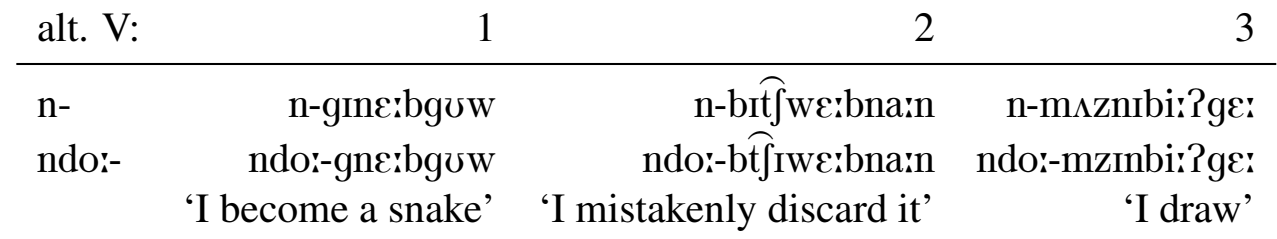

As in the prefix survey, all participants were shown short lists of plausibly familiar words from each partition. Words were otherwise drawn randomly from each partition, though the number of draws from each partition was not actively balanced. The order in which prefixed variants were displayed on the screen varied randomly between trials.

Additionally, foil trials were randomly interspersed amongst the test trials. In a foil trial, all of the vowels that uniquely occurred under prefixation were replaced with a randomly selected short vowel. That is, the $[\Lambda]$ of n-mıkzIn uniquely occurs under prefixation, while the [I] also occurs in the unprefixed form, as seen in mkızIn. In a foil trial, the $[\Lambda]$ could be replaced with either [I] or [ $\mho]$, producing, for instance, n-mIkzIn in place of n-mukzIn). These foil trials were included to check whether participants who selected conservative forms knew the true conservative form. Since foil trials did not directly address the central question of the survey (whether participants prefer innovative or conservative forms), the number of foil trials was capped at 5 per participant. The survey ended when participants completed 30 non-foil trials. A total of 581 forced-choice evaluations were collected from 20 participants. The number is less than 600 because one participant did not complete all trials. 


\subsection{Leveling Survey Results}

The leveling survey results affirm that historically alternating stems now take the innovative prefixes, as suggested by Rhodes $(1975 ; 1985 \mathrm{a} ; 1985 \mathrm{~b})$ and Piggott (1980 [1974]). Participants overwhelmingly selected leveled forms (ndo:-mkIzIn 'my shoe') over alternating forms (n-mıkzIn 'my shoe'). Contrary to Valentine (2001), highly proficient speakers did not reliably select historical forms, as seen in the top left panel of Figure 2. ${ }^{14}$ Furthermore, the two speakers who selected historical forms nearly three-quarters of the time also picked foil items at a comparable rate, which suggests that they had adopted a strategy of merely selecting conservative-looking forms, regardless of whether they were actually in the language. Increased word familiarity increased the likelihood of the historical form being selected, as can be seen in the bottom left panel of Figure 2. The top right panel of Figure 2 illustrates that contrary to the prefix suvey, older speakers picked historical forms less often than younger speakers did. Finally, in a striking result, the bottom right panel of Figure 2 shows that as the number of alternating vowels increases, participants grow less likely to select historical forms.

\subsubsection{Model Construction Parameters}

Statistical analysis confirms these impressions. Generalized linear mixed effects models predicting the choice between innovative and conservative forms with a random intercept for speaker were fitted using the glmer() function from the lme 4 package in R. As in the prefix survey, model predictors could include zero or more of speaker age, speaker proficiency or word familiarity. The rate at which each participant selected unattested conservative foil forms was also included as a potential predictor.

Except when specified otherwise, models also included a factor to measure the effect of multiple vowel-zero alternations. A reviewer helpfully points out that the number of alternations may be best coded as a binary factor for one-vs-many alternations, since forms with 2-4 alternating vowels are selected at about the same rate. Models fitted under this binned coding scheme fit slightly better, and thus will be used below, though no claims are made regarding whether Nishnaabemwin speakers have a binary one-vs-many dispreference or a gradient one.

\footnotetext{
${ }^{14}$ Comparison of Figure 2 and Figure 1 shows that the only speaker who selected historical forms more than $75 \%$ of the time in the prefix survey did not do so in this survey. Thus, no speaker in the study approached a categorical preference for historical forms.
} 

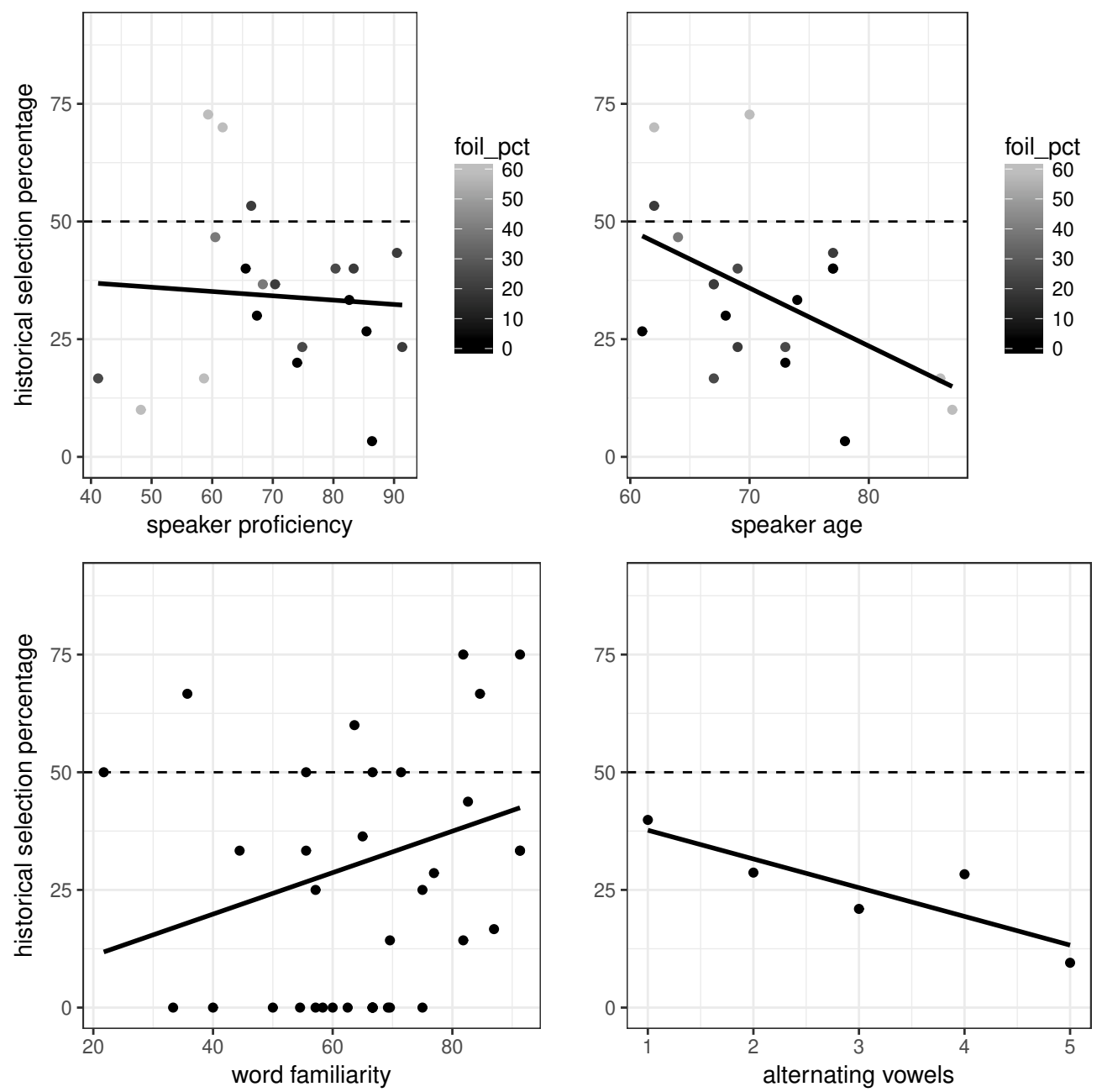

Figure 2: Plots of leveling survey results. Dashed lines mark 50\% (chance) historical selection rate. Top left panel: speaker-by-speaker plot of percentage of historical forms selected, by proficiency score. Top right panel: speaker-by-speaker plot of percentage of historical forms selected by age. In both top panels, a lighter color indicates that the speaker accepted foil forms at a higher rate. Bottom left panel: percentage of times historical form was selected by word familiarity score, for words that were sampled 4 or more times. Bottom right panel: percentage of historical forms selected, by number of alternating vowels. 
Finally, 1930's Nishnaabemwin forms often contain local morphological ambiguities, which could prompt participants to avoid a historical form and select the unambiguous innovative form instead. The first such ambiguity lies in prefixed forms that historically began with $n-g \Lambda$, which is locally ambiguous with a parse of '1-FUT' $n-g_{\Lambda}-$. The second such factor is whether the 1930's Nishnaabemwin form began with $n-d \Lambda, n-d I$ or $n-d v$, the first two of which were locally ambiguous with an extended allomorph parse (nd $\Lambda^{-}$or $\left.n d I^{-}\right) .{ }^{15}$ Both of these ambiguities were coded with binary categorical variables for whether the conservative form began with the relevant sequence.

\subsubsection{Hypothesis Testing and Model Selection}

Like the prefix survey, this survey probes the extent of restructuring in modern Nishnaabemwin. This survey asked participants to choose between a conservative form and an innovative ndo:- form. As a result, the extent of restructuring is reflected in how often participants selected innovative forms over conservative forms. As is already clear from Figure 2, participants overwhelmingly selected innovative forms.

While the clear avoidance of conservative forms is already established, the results can shed light on what influences the probability that an innovative form will be chosen. Most pressing is Valentine's $(2001$; 1994) hypothesis that highly proficient speakers prefer conservative patterns. The null hypothesis in this case cannot be rejected $(p=0.8943, \Delta \mathrm{AIC}=-1.98)$. Proficiency is not a reliable predictor of whether a speaker prefers innovative forms over conservative forms.

Additionally, models containing different combinations of the factors listed above were compared on AIC and $p$-values. The best model of the data includes age, but excludes speaker proficiency and word familiarity. ${ }^{16}$ The best model significantly improves fit relative to an intercept-only model $(p<0.001$, $\triangle \mathrm{AIC}=29.3$ ). Model fit was not significantly improved in models that also included word familiarity $(p=0.6935 \Delta$ AIC $=-1.9)$, speaker proficiency $(p=$ $0.3265, \Delta \mathrm{AIC}=-1)$, or all three predictors $(p=0.578, \Delta \mathrm{AIC}=-2.9)$. The best model has substantially better fit than models that do not contain a subset or superset of its predictors. This includes models with only speaker proficiency $(\triangle \mathrm{AIC}=9.3)$ or word familiarity $(\triangle \mathrm{AIC}=9.5)$.

\footnotetext{
${ }^{15}$ No ready explanation presents itself for why the coefficients of these local ambiguities have different polarities in (19).

${ }^{16}$ A convergence warning was issued when fitting this model, but the bobyqa optimizer successfully fit the model with no substantial differences from the original model.
} 


\subsubsection{Model Criticism}

The table in (19) shows the fixed effects of the maximal model, where negative coefficients indicate that a predictor improves the odds of the innovative form (ndo:-mkizin) and positive coefficients improve the odds of the historical form $\left(n-m_{A} k z I n\right)$. Predictors that are not present in the best model are italicized.

$\begin{array}{lrrrrl} & \text { Estimate } & \text { Std. Error } & \mathrm{z} \text { value } & \operatorname{Pr}(>|z|) & \\ \text { (Intercept) } & -0.946649 & 0.261456 & -3.621 & 0.000294 & * * * \\ \text { age(z-scored) } & -0.511188 & 0.145574 & -3.512 & 0.000446 & * * * \\ \text { familiarity(z-scored) } & 0.035012 & 0.095443 & 0.367 & 0.713741 & \\ \text { proficiency(z-scored) } & 0.175473 & 0.179200 & 0.979 & 0.327478 & \\ \text { AltVowels }>1 & -0.808641 & 0.198504 & -4.074 & 4.63 \mathrm{e}-05 & * * * \\ \mathrm{n}-\mathrm{g \Lambda} & -0.747303 & 0.489440 & -1.527 & 0.126798 & \\ \mathrm{n} \text {-dV } & 0.881623 & 0.311641 & 2.829 & 0.004670 & * * \\ \text { \%foil accepted } & 0.019439 & 0.008228 & 2.363 & 0.018145 & *\end{array}$

The key confirmation is that historical forms are strongly dispreferred, as can be seen in Figure 2, where rates of choosing the historical form strongly tend below $50 \%$. That is, in addition to the baseline tendency to accept innovative forms represented in the intercept, there is also a large effect favoring the selection of innovative forms when there would be multiple vowel-zero alternations in the conservative form. Historical forms stand the best chance of being selected if the speaker is younger than average, or if the historical form is locally ambiguous with an innovative prefix. Notably, the effect of age is smaller than the effect of multiple alternating vowels being present. That is, in order for a historical form to be favored when multiple vowels alternate, the speaker must be more than one standard deviation younger than the survey average. The dispreference against historical forms underlines the major result of the prefix allomorph survey: the cohort has substantively abandoned 1930's Nishnaabemwin forms.

\subsubsection{Local Discussion}

These results are inconsistent with Valentine's (2001) claim that highly proficient speakers continue to prefer 1930's Nishnaabemwin forms. Speaker proficiency has a non-significant effect in (19), and speaker age, which might be expected to be correlated with greater facility with 1930's Nishnaabemwin, is associated with an increased dispreference against 1930's Nishnaabemwin forms.

The negative correlation of age with preference for 1930's Nishnaabemwin forms is somewhat surprising, especially since age had an insubstantial effect in 
the prefix survey. It is possible that social desirability is responsible for this effect. 1930's Nishnaabemwin forms are prestigious in a society that values age and traditional knowledge. Under this explanation, the younger speakers selected 1930's Nishnaabemwin forms for their prestige, while older speakers do not need to lay claim to prestige forms. ${ }^{17}$ Tentative support for this explanation comes from the fact that the two younger speakers who selected conservative forms most frequently also selected foils like *n-mokzIn (in place of attested n-mukzIn 'my shoe') three out of five times, the highest rate observed in the study (see the upper right panel of Figure 2). These participants may have been determined enough to select conservative forms that they even selected false conservative forms. Strikingly, these speakers drive the correlation with age, as omitting speakers who selected foil forms $60 \%$ of the time causes speaker age to no longer be be a reliable predictor.

In sum, the answer to the second research question posed in section 2.5 is that speakers strongly prefer innovative forms over conservative forms with alternations. The prefix survey and the leveling survey together show that the restructuring cohort has uniformly adopted the innovative system; no sub-group maintains the conservative pattern. The next survey assesses whether the innovations are the result of attrition or otherwise imperfect knowledge of the 1930's pattern.

\section{Survey 3: Alternation Accuracy}

The previous two surveys have shown that non-etymological prefixation and paradigm leveling are the predominant patterns for the restructuring cohort. The third survey sought to address the third research question in section 2.5 by testing whether speakers can distinguish 1930's Nishnaabemwin prefixed forms from foils. The concern is that a lack of primary linguistic data may have impeded these speakers from acquiring a 1930's Nishnaabemwin-style deletion process. If speakers abandoned 1930's Nishnaabemwin prefixation and alternations because of insufficient data, they would be expected to distinguish poorly between actually attested 1930's Nishnaabemwin prefixed forms and unattested foils.

The procedure was nearly identical to the one used in the leveling survey. Speakers were asked to choose the best out of two potential 1930's Nishnaabemwin prefixed forms. In this survey, the choice was between a historical prefixed

\footnotetext{
${ }^{17}$ The reader may wonder why a similar age effect was not observed in the prefix survey. Note that in the prefix survey there was not a clear differentiation between the actual historical form and its competitors, while in this survey it was a binary choice between dramatically different forms.
} 
form and a foil form. That is, the choice for the prefixed form of mkizin 'shoe' was between n-mıkzIn 'my shoe' and a prefixed form where random, distinct short vowels replaced all vowels that only ocurred in the 1930's Nishnaabemwin prefixed form, like *n-məkzIn 'my shoe'.

Participants were not given any prior information about the forms they would be evaluating, but were told that there would be two alternatives of which one had to be chosen. Words were randomly drawn from the same lists used in the leveling survey, though no participant was shown the same word in both surveys. The survey ran until speakers recognized and evaluated 30 words. A total of 597 forced-choice judgements were collected, as one speaker did not complete all trials.

\subsection{Alternation Accuracy Survey Results}

All speakers preferred attested 1930's Nishnaabemwin forms over foils. This can be seen in the top panels of Figure 3, which plot the rate at which individual speakers chose attested 1930's Nishnaabemwin forms by proficiency and age. Furthermore, word familiarity, but not the number of alternating vowels, is positively correlated with the rate at which 1930's Nishnaabemwin forms were selected (Figure 3 bottom panels).

\subsubsection{Model Construction Parameters}

As in the previous surveys, generalized linear mixed effects models predicting whether the conservative form or a foil was selected were fitted to the data. All models included random intercepts for speaker. As before, models included zero or more of word familiarity, speaker age, or speaker proficiency. Except where explicitly noted, all non-empty models also included the number of alternating vowels (binned between 1 or more) and whether a form had a local ambiguity with the parse $n-g_{\Lambda^{-}}$' 1 -FUT-'. 18

\subsubsection{Hypothesis Testing and Model Selection}

This survey probes whether speakers can reliably differentiate between true 1930's prefixed forms and foils. The test hypothesis is that speakers prefer true 1930's

\footnotetext{
${ }^{18}$ In the leveling survey, the conservative form of [d]-initial stems could be locally ambiguous between $n-d V$ and $n d V$-. Because this survey deals exclusively with potential conservative forms, both options on [d]-initial stems have the same ambiguity, and no factor tracking this was included.
} 

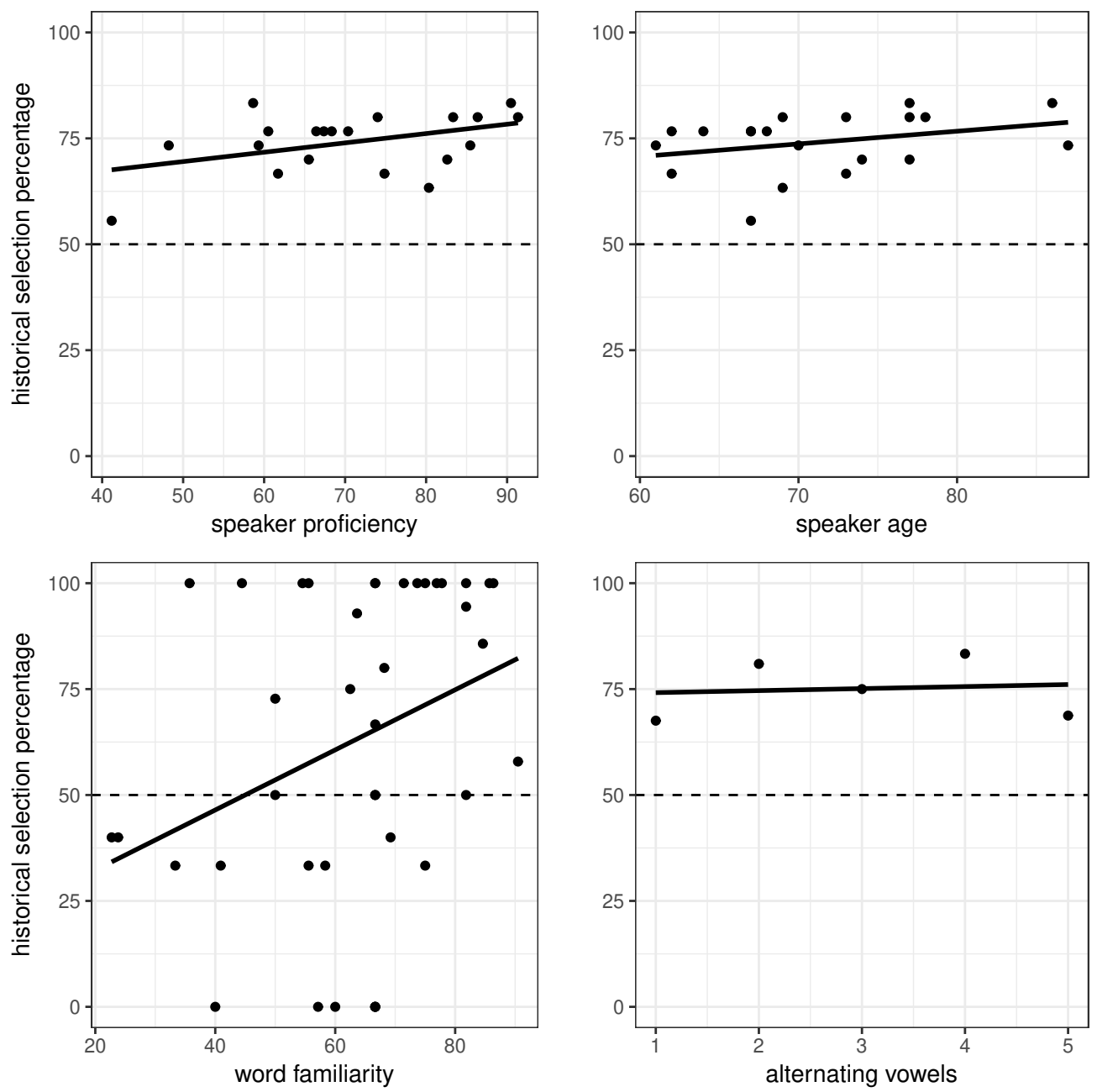

Figure 3: Graphs of alternation accuracy survey results. Dashed lines mark 50\% (chance) historical selection rate. Top left panel: speaker-by-speaker plot of percentage of historical forms selected, by proficiency score. Top right panel: speaker-by-speaker plot of percentage of historical forms selected, by age. Bottom left panel: percentage of times the historical form was selected by word familiarity score, for words that were sampled four or more times. Bottom right panel: percentage of historical forms selected, by number of alternating vowels. 
prefixed forms to foils, while the null hypothesis (dubbed the 'attrition hypothesis' here) is that participants do not do so. If the attrition hypothesis is true, a likely cause is that speakers of the innovative modern language do not know the true 1930's prefixed forms, so speakers should choose foils and real 1930's prefixed forms at approximately the same rate. The attrition hypothesis is not supported, since speakers select true 1930's prefixed forms much more frequently than foils. Outright ignorance cannot be the explanation for the rise of restructuring across the entire cohort.

However, we still might expect to find echoes of attrition in this data. Specifically, speaker proficiency could predict whether conservative forms were selected over foils. In this case we would expect low estimated vocabulary size to impede selection of conservative forms. This is not the case, as a model including only speaker proficiency does not significantly improve fit over an empty model $(p=0.1198, \Delta \mathrm{AIC}=0.42) .{ }^{19}$

AIC scores indicate that several models fit the data roughly equally well. The model with the lowest AIC score included word familiarity and speaker proficiency (AIC=672.46), but similar AIC scores were obtained by models containing just word familiarity $(\mathrm{AIC}=673.14$ ), word familiarity and speaker age $(\mathrm{AIC}=673.45)$ and all three of these predictors $(\mathrm{AIC}=672.62)$. The least complex of these models (the one that only includes word familiarity) should be preferred, as none of the more complex models fit the data significantly better (familiarity and proficiency: $p=0.1014$, familiarity and age: $p=0.1938$, familiarity, proficiency and age: $p=0.1042$ ).

\subsubsection{Model Criticism}

The table in (20) shows the fixed effects for the maximal model (containing proficiency, familiarity and age as predictors). Positive coefficients correspond to an increase in the likelihood that the attested form is chosen. Predictors that do not appear in the best model are italicized.

\footnotetext{
${ }^{19}$ The absence of a proficiency effect could be ascribed to participants only stating they knew a word if they were confident in its 1930's prefixed form, thereby improving accuracy on this task. In such a situation, speakers would be expected to say they knew words less often in this survey, which directly tested command of 1930's forms, than in the other surveys. This was tested with a linear model predicting the rate each speaker claimed to know words in the alternation survey by the same rate in the prefix and leveling surveys. This model has an intercept at 0.07 and a slope of $0.91\left(r^{2}=0.61\right)$. In other words, speakers stated they knew words at almost exactly the same rate across surveys.
} 


\begin{tabular}{|c|c|c|c|c|c|}
\hline & Estimate & Std. Error & $z$ value & $\operatorname{Pr}(>|z|)$ & \\
\hline (Intercept) & 0.759674 & 0.140853 & 5.393 & $6.91 \mathrm{e}-08$ & $* * *$ \\
\hline proficiency(z-scored) & 0.171463 & 0.101866 & 1.683 & 0.092333 & \\
\hline age $(z$-scored $)$ & 0.129810 & 0.096367 & 1.347 & 0.177971 & \\
\hline familiarity(z-scored) & 0.296874 & 0.106567 & 2.786 & 0.005340 & ** \\
\hline \#AltVowels > 1 & 0.664969 & 0.193227 & 3.441 & 0.000579 & ** \\
\hline $\mathrm{n}-\mathrm{g} \Lambda$ & -0.007046 & 0.313011 & -0.023 & 0.982040 & \\
\hline
\end{tabular}

The model estimates that historical forms are selected at a much higher rate than foils, as reflected in the intercept value. This is significantly augmented by the effect of word familiarity, and whether there were multiple alternating vowels.

\subsubsection{Local Discussion}

The earlier surveys establish that when choosing between historical forms and innovative forms, participants prefer innovative forms. This study shows that participants can reliably distinguish between historical prefixed forms and unattested foils. This suggests that speakers have fairly accurate knowledge of 1930's Nishnaabemwin alternations, despite having abandoned the historical system.

Note that we cannot disprove that the historical pattern was abandoned due to insufficient exposure. After all, we do not even know how much exposure to rhythmic syncope is enough to acquire it. But we can reject the proposition that the target cohort had dramatically impoverished experience with the old system. In fact, participants' accuracy in this task is remarkable when we consider that the task is somewhat unnatural and they are evaluating forms that must have been largely unused for several decades.

\section{Analysis of Modern Nishnaabemwin}

To summarize the major empirical results, the goals from section 2.5 are repeated below with the corresponding results.

- Establish the rate of application for innovative prefix allomorphs and establish whether innovative prefixation occurs on historically non-alternating stems for any speakers.

- Innovative prefix allomorphs are widely accepted on non-alternating stems. 
- Assess the degree to which speakers prefer innovative prefixation plus leveling over conservative prefixation plus alternation.

- Innovative prefixation is very strongly preferred to conservative prefixation with alternation.

- Assess speakers' familiarity with 1930's Nishnaabemwin forms.

- Participants reliably distinguish 1930's Nishnaabemwin forms from foils, indicating that speakers are familiar with 1930's Nishnaabemwin forms.

- Probe whether proficiency, age or word familiarity influence the use of innovative prefixation or conservative prefixation.

- Highly familiar words favored conservative forms in the first and third surveys.

- Highly proficient speakers favored conservative forms in the rating task of the prefix (first) survey but not in the other surveys.

- Older speakers potentially disfavored conservative forms in the leveling (second) survey.

- In the first two surveys, which pitted innovative forms against conservative forms, the effects favoring conservative forms were substantially smaller than the effects favoring innovative forms.

With the change in the language established, we can now ask whether the grammar changed as well. This section contrasts a recapitulationist analysis, which posits synchronic rhythmic syncope in modern Nishnaabemwin (Valentine 1994; 2001) with a restructuring analysis. Section 7.3 argues in favor of the restructuring analysis by highlighting theoretical and empirical difficulties for the recapitulationist analysis.

\subsection{Restructuring Analysis}

A restructuring analysis is quite simple. Underlying forms, to a very good first approximation (Bowers 2015:ch 5), correspond to 1930's Nishnaabemwin isolation forms, and person prefixes $n d_{\Lambda^{-}}, n d_{I^{-}}, n d o_{-}^{-}$, and even $n-$, or $n d-$ are probabilistically deployed according to a speaker's preference for particular allomorphs (Bowers 2012). There is no need for the grammar to build and destroy iambic feet 
under this analysis, because all of the missing etymological vowels are already absent from underlying representations. Hence, modern Odawa leveled paradigms are generated via the identity map, so that /mkızın/ $\rightarrow$ [mkızın] 'shoe', and /ndo:mkızın/ $\rightarrow$ [ndo:mkızın] 'my shoe'. Prefixed forms like *nmkızın, or *ndmkızın 'my shoe' are ruled out by presumably high-ranked phonotactic constraints, as the word-initial clusters in such forms were unattested in 1930's Nishnaabemwin.

Central to the analysis of modern Nishnaabemwin is the continued acceptance of 1930's prefixed forms. Under a restructuring analysis, 1930's Nishnaabemwin alternations are irregular. That is, the 1930's form for 'my shoe' is stored whole as [n-mıkzIn] and produced without alteration. Deriving 1930's Nishnaabemwin alternations via a general, regular rule is impossible if etymological vowels have been lost from URs. For instance, from a restructured UR like /mkizIn/ 'shoe', vowels that appeared only in 1930's Nishnaabemwin prefixed forms, like the $[\Lambda]$ in [nmskzin] 'my shoe', would need to be epenthesized. With three short vowels $[\Lambda, \mathrm{I}, \mho]$ to potentially epenthesize, such a procedure is not generally applicable.

There is some independent evidence for 1930's forms being listed irregulars, as many speakers in the study reported that regular innovative forms had compositional meanings, while 1930's prefixed forms had idiosyncratic meanings. For instance, one participant reported that the innovative form ndo:-go: $\widehat{d z}$ In means 'I hang' (cf. go: $\widehat{d}_{3}$ In 'he hangs'), while the conservative form nds-go:d ${ }_{3}$ In means 'I fall'. This is reminiscent of the state of affairs in Tongan with respect to regularized and etymological suffix allomorphs (Kie Zuraw, p.c.), see also Hale (1973; 1991:100) on Maori.

A restructuring analysis, because it merely carries out the identity map and selects prefix allomorphs, is compatible with any modern theory of grammar. Only the variability in prefix allomorph choice requires any departure from default grammatical mechanisms. A full analysis could be couched in any popular theory like Partial-Order OT (Anttila 1997), Stochastic OT (Boersma 1997, Boersma and Hayes 2001), Noisy Harmonic Grammar (Boersma and Pater 2008), or the Maximum Entropy method in Harmonic Grammar (Goldwater and Johnson 2003).

\subsection{Recapitulationist Analysis}

A recapitulationist analysis of modern Nishnaabemwin posits that underlying forms have not restructured, and that vowels continue to delete in an alternating pattern 
(Valentine 2001:65-66, 79-80, see also Valentine 1994:147-8 on Potawatomi). ${ }^{20}$ For convenience, the recapitulationist grammar is assumed to enforce a serial interaction between stress and syncope (McCarthy 2008), though a subregular transducer obeying certain properties can also compute the mapping (Bowers and Hao 2018). ${ }^{21}$

In order to generate rhythmic syncope alternations, $n$ - must shift foot boundaries leftward by incorporating into a foot with stem material. Meanwhile, in order to condition non-alternation, innovative prefixes must be followed by a foot boundary; this is inevitable for the prefix ndo:-, but $n d_{\Lambda}$ - and $n d I^{-}$must be bisyllabic. This can be ensured by assuming that person prefixes contain syllabic consonants (see Valentine 2001:74), yielding URs like /n-/ or $/ \mathrm{nd}_{\Lambda} \Lambda_{-} / .^{22}$ Under the recapitulationist theory, the absence of overt alternations between mkIzIn 'shoe' and ndo:-mkizin 'my shoe' is the result of new person prefixes being followed by a foot boundary. Thus, whether a stem is preceded by a new person prefix or appears in isolation, its vowels will always be parsed into the same foot position, as in $\left(m \_k i ́\right)(z i ́ n)$ 'shoe' and (ndo:-) $\left(m_{-} \_\right.$kí)(zín) 'my shoe'. This is illustrated in the derivation in (21).

\begin{tabular}{|c|c|c|}
\hline 'shoe' & 'my shoe' & New (recapitulationist) \\
\hline$/ \mathrm{m} \wedge \mathrm{kIzII}$ & /ṇdo:-mıkızin/ & UR \\
\hline (zín) & (ṇdó:)(m^kí)(zín) & Stress \\
\hline (zín) & (ṇdó:)(mkí)(zín) & Syncope \\
\hline akızın] & [ndo:mkızin] & SR \\
\hline
\end{tabular}

\footnotetext{
${ }^{20}$ In a separate publication, Valentine (in Medler 1998:8) raises the possibility that "many contemporary speakers have arguably gone so far as to lose some of these short [syncopated] vowels in their underlying representations". Which syncopated vowels are missing from the URs of which speakers is not addressed in the recapitulationist analysis found in Valentine (2001), though Valentine (1994:150) suggests that only heavily attrited speakers have lost etymological vowels.

${ }^{21}$ In a serial implementation, it may be difficult to capture some effects from the surveys, like the dispreference against multiple vowel-zero alternations. Avoiding multiple vowel-zero alternations seems to require comparing the outputs of derivations, so that ndo-bna:kwe: is more likely than $n$-bına:kwe: 'I harvest (from stalks)' (1 alternating vowel), but ndor-bd $\Delta k \int k \Lambda ? g_{\Lambda} n$ is even more

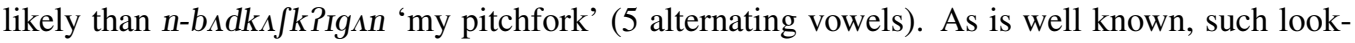
ahead is standardly avoided in serialist models of phonology.

${ }^{22}$ This is a slight departure from Valentine (2001), who assumes URs with a perpetually deleted vowel, as in $/$ nId $\Lambda-$. This assumption allows innovative third person prefixes to be generated. The third person prefix was historically $/ \mho-/$, and consequently the innovative third person prefix allomorphs are $d_{\Lambda-}, d_{I-}$ and $d_{o} s^{-}$, which appear in noun possession. In order to generate $d_{\Lambda}$-mkIzIn 'his shoe', the recapitulationist analysis must assume two vowels in the prefix, as in $/ v \mathrm{~d}_{\Lambda}$-mskizın/ $\rightarrow\left(\mho \mathrm{d} \hat{L}^{-}\right)(\mathrm{m} \wedge k \hat{i})(\mathrm{zín}) \rightarrow\left[\left(\mathrm{d} \hat{\Lambda}^{-}\right)(\mathrm{m}\right.$ kí)$\left.)(\mathrm{zín})\right]$. Omitting the extra vowel from the UR produces an

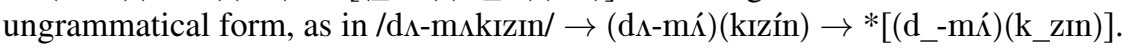


Because of the neat correspondence between foot boundaries and innovative prefix boundaries, under the recapitulationist account, the lexicon and grammar of Nishnaabemwin remain substantially the same as 1930's Nishnaabemwin. The only major differences between 1930's Nishnaabemwin and modern Nishnaabemwin are that phonetic reduction is now phonological deletion, and that innovative prefix allomorphs have been created.

Note that the development of innovative prefix allomorphs must be stipulated in a recapitulationist account. Under a rhythmic syncope grammar, the presence

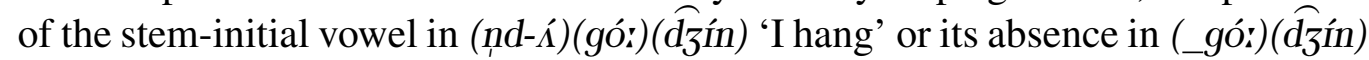
'he hangs' has a perfectly sound phonological explanation, where the stem vowel remains part of the stem, yielding / go:d $3 \mathrm{In} /$, and it deletes following the general rhythmic syncope pattern. No innovation would therefore be expected in the language, and 1930's Nishnaabemwin would have been veridically phonologized.

An important apparent benefit of a recapitulationist analysis is that it need not resort to listing 1930's Nishnaabemwin prefixed forms, since it generates them directly from the UR when an appropriate prefix is used. For instance, forms like n-mıkzın 'my shoe' are analyzed as the result of /n-mıkızın/ $\rightarrow$ (nmí)(kızín) $\rightarrow$ [nmskzIn]. However, section 7.3 shows that continued syncopation is a liability for the recapitulationist analysis.

\subsection{Distinguishing Restructuring from Recapitulation}

Wider descriptive facts weigh against the recapitulationist analysis of modern Nishnaabemwin. As seen in example (21), the recapitulationist analysis generates modern leveled paradigms by attaching an innovative prefix to a historically alter-

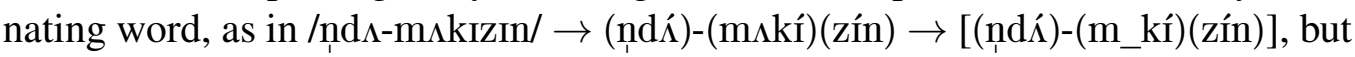
it can also attach a conservative prefix to produce a conservative prefixed form, as in /n-mıkızın/ $\rightarrow$ (n-mí) (kızín) $\rightarrow$ [(n-mú)(k_zín)] 'my shoe'. However, this result only holds for consonant-initial alternating words. The recapitulationist analysis predicts that alternating words that began with a short vowel (VCV words) will overapply deletion. To see this, first consider the 1930's derivation of / $\Lambda$ nzki:/ 'work' in (22). 


\begin{tabular}{|c|c|c|}
\hline 'He works' & 'I work' & 1930’s \\
\hline /Anvki:/ & /nI- $\Lambda$ nvki:/ & UR \\
\hline - & nId $\Lambda$ nvki: & Hiatus Resolution \\
\hline$(\Lambda \mathrm{n} ̛ ́)(\mathrm{kí}:)$ & 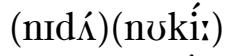 & Stress \\
\hline (ílis) & $\left(\mathrm{n}^{\ni} \mathrm{d} \hat{\Lambda}\right)\left(\mathrm{n}^{\ni} \mathrm{k}^{\prime} \mathrm{i}\right)$ & Reduction \\
\hline${ }^{\partial}$ nứkíi:] & [n ${ }^{\partial} \mathrm{d} \hat{n} \mathrm{n}^{\ominus} \mathrm{kí}$ ] & SR \\
\hline
\end{tabular}

Recall from section 2.2.1 that stem-initial short vowels were parsed into the prefix, thereby creating the innovative prefix allomorphs. Concretely, learners exposed to 1930's Nishnaabemwin analyzed [ndınkii:] as [(ndí)-(n_kíi)] 'I work'. As a result, the underlying representation for 'work' is /nzki:/, [ $v$ ] being supplied from the unaffixed form [noki:] 'he works'. The recapitulationist analysis thus predicts that modern speakers should produce the paradigm in (23):

\begin{tabular}{|c|c|c|c|}
\hline 'He works' & 'I work' (innov. prefix) & 'I work' (cons. prefix) & New (recapitulationist) \\
\hline /nvki:/ & /nd $\Lambda$-nひki:/ & /n-noki:/ & UR \\
\hline (nvkíi) & $($ ndó)(nひkí:) & $\left(n+u_{1}^{\prime}\right)\left(k^{\prime} \dot{i}\right)$ & Stress \\
\hline (n_kíi) & $($ ndó) (n_ḱí) & $(n n ̛ o ̛)(k \dot{i})$ & Syncope \\
\hline$*[$ nkíi: $]$ & [ndínkí:] & [nnớkí:] & SR \\
\hline
\end{tabular}

According to Rhodes (1985a; 1985b:467), modern speakers produce noki: 'he works', nd $\Lambda$-nzki: 'I work' (with $n d \Lambda$ - standing in for any innovative prefix), and less frequently, the conservative form nd $n$ nki: 'I work' alongside another innovative form n-nzki. The recapitulationist analysis must include the original steminitial vowel in the UR to prevent the vowel [ $\mho]$ from obligatorily deleting in isolation forms and after innovative prefixes. That is, with all original vowels in-

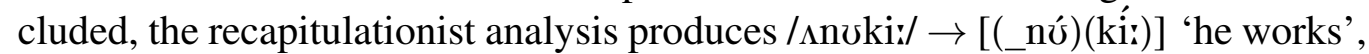

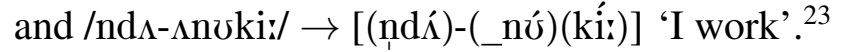

Adopting this analysis requires an internally inconsistent view of the rise of the innovative prefix allomorphs (see Valentine 1994:148 for early acknowledgement of the inconsistency). An underlying representation like / $\Lambda$ n $\mho \mathrm{ki}$ // can only exist if the morphological boundary between prefix and stem is not reanalyzed from $n[d]-\Lambda n k i:$ to nd $\Lambda$-nki. However, the most salient aspect of the modern language is that the innovative prefix allomorphs have cascaded across the lexicon, making

\footnotetext{
${ }^{23}$ The preservation of the stem-initial [v] in modern nds-nvki: 'I work' or nvki: 'he works' cannot be due to stem-initial faithfulness in a recapitulationist analysis, as vowels in other stem-initial syllables, like /mıkızın/ are then falsely predicted to surface as in *(mıkí)(zín) 'shoe' or *(ndí)(makí)(zín). See Bowers (2012) for discussion of the potential role of stem-initial faithfulness in a restructuring analysis.
} 
it all but certain that the reanalysis occurred. The recapitulationist analysis must therefore propose that a rhythmic syncope grammar and the correct morphological affiliations were found by learners, but that learners nonetheless changed the language away from the veridical rhythmic syncope system.

In contrast, the restructuring analysis states that the UR is /nvki:/, and the modern paradigm is generated seamlessly by the identity map, as in /nvki:/ $\rightarrow$ [nvki:]

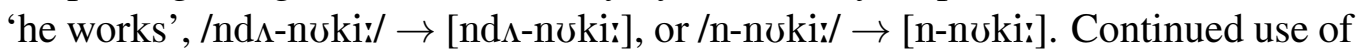
the historical form ndsnkir is carried out by lexical listing.

In sum, a restructuring analysis either misgenerates or results in contradiction when innovative prefixes on VCV words are considered. A restructuring account does not suffer from this problem.

\section{Conclusion}

The surveys have confirmed that Nishnaabemwin was thoroughly restructured by the generation born during and after the 1930's, in line with contemporary reports (Piggott 1980 [1974], Rhodes 1975; 1985a; 1985b). In both the prefix allomorph survey and the leveling survey, participants preferred innovative forms over 1930's Nishnaabemwin forms. The results from the alternation accuracy survey show that participants did not avoid 1930's Nishnaabemwin forms out of a lack of familiarity, as they reliably distinguished them from foils. Modern Nishnaabemwin thus arose from 1930's Nishnaabemwin despite what could only have been substantial exposure to the 1930's system.

The mere observation that a change occurred is not sufficient; we also seek a description of the grammar of modern Nishnaabemwin. The critical question is whether the phonological grammar recapitulates 1930's Nishnaabemwin with a phonological rhythmic syncope process, or whether the phonology has been restructured so that the grammar no longer actively enforces rhythmic syncope. Although a restructuring analysis appeals to large-scale memorization of 1930's forms, it does not invite a contradictory view of the observed restructuring while still avoiding misgenerating modern forms.

The shift away from 1930's Nishnaabemwin is clearly relevant to phonological theory. The prefix survey highlights the breakdown of a tidy allophonic system, while the leveling survey illustrates a sharp dispreference against 1930's alternations. Such a response to a phonological system strongly suggests that learners had great difficulty with it and ultimately did not acquire it. It is interesting to note that there are other aspects of Nishnaabemwin morphophonology, not discussed 
here, that by all accounts were faithfully transmitted to current speakers. First, 1930's Nishnaabemwin had an apocope process that deletes at least word-final short vowels, which has not changed (see Piggott 1980 [1974], 1983:84, Valentine 2001:215). Second, 1930's Nishnaabemwin had an intricate inflectional class system in noun suffixation, and this has not changed either (see Jones 1971, Valentine 2001:174). Learners instead specifically rejected rhythmic syncope, which suggests that it may not be safe to assume that rhythmic syncope is easily acquired by learners. In the event that this difficulty is general, an explanation is needed. Such an explanation could lie in the difficulty of inferring the correct representations for rhythmic syncope derivations, or in inducing the serial interaction between stress and syncope, or most strongly, the explanation could lie in the actual absence of the appropriate architecture for rhythmic syncope.

\section{References}

Albright, A. and B. Hayes (2003). Rules vs analogy in English past tenses: A computational/experimental study. Cognition 90, 119-161.

Anttila, A. (1997). Deriving variation from grammar: A study of Finnish genitives. In F. Hinskens, R. van Hout, and L. Wetzels (Eds.), Variation, Change and Phonological Theory. Amsterdam: John Benjamins.

Bates, D., M. Mächler, B. Bolker, and S. Walker (2015). Fitting linear mixedeffects models using lme4. Journal of Statistical Software 67(1), 1-48.

Bermúdez-Otero, R. (2007). Diachronic phonology. In P. de Lacy (Ed.), The Cambridge Handbook of Phonology. Cambridge University Press.

Bermúdez-Otero, R. (2014). Amphichronic explanation and the life cycle of phonological processes. In P. Honeybone and J. C. Salmons (Eds.), The Oxford handbook of Historical Phonology. Oxford University Press.

Bloch, B. (1938). My Chippewa transcription, impressionistic and 'systematized' (i.e. quasi-phonemicized by snap judgement inspection), corrected by Leonard Bloomfield. Smithsonian National Museum of Natural History, National Anthropological Archives, Leonard Bloomfield Papers Collection, Folder B. Bloch - Ojibwa. 
Bloomfield, L. (1957). Eastern Ojibwa: Grammatical Sketch, Texts and Word List. Ann Arbor: University of Michigan Press.

Blumenfeld, L. (2006). Constraints on Phonological Interactions. Ph. D. thesis, Stanford.

Boersma, P. (1997). How we learn variation, optionality and probability. In Proceedings of the Institute of Phonetic Sciences of the University of Amsterdam 21, pp. 43-58.

Boersma, P. and B. Hayes (2001). Empirical tests of the Gradual Learning Algorithm. Linguistic Inquiry $\underline{32}$ (1), 45-86.

Boersma, P. and J. Pater (2016 [2008]). Convergence properties of a gradual learning algorithm for Harmonic Grammar. In J. McCarthy and J. Pater (Eds.), Harmonic Grammar and Harmonic Serialism, pp. 389-434. Equinox Press.

Bowers, D. (2012). Phonological restructuring in Odawa. Master's thesis, University of California, Los Angeles.

Bowers, D. (2015). A System for Morphophonological Learning and its Consequences for Language Change. Ph. D. thesis, UCLA.

Bowers, D., A. Arppe, J. Lachler, S. Moshagen, and T. Trosterud (2017). A morphological parser for Odawa. In M. Hulden (Ed.), Proceedings of the Second Workshop on Computational Methods for Endangered Languages, pp. 1-9. Association for Computational Linguistics.

Bowers, D. and Y. Hao (2018). The formal complexity of rhythmic syncope. University of Arizona and Yale University ms.

Brysbaert, M., M. Stevens, P. Mandera, and E. Keullers (2016). How many words do we know? practical estimates of vocabulary size dependent on word definition, the degree of language input and the participant's age. Frontiers in Psychology 7.

Bybee, J. (2001). Phonology and Language Use. Number 94 in Cambridge Studies in Linguistics. Cambridge University Press.

Corbiere, M. A. and J. R. Valentine (2016). Nishnaabemwin: Odawa and Eastern Ojibwe online dictionary. Last checked: June 52017. 
Goldwater, S. and M. Johnson (2003). Learning OT constraint rankings using a Maximum Entropy model. In J. Spenader, A. Eriksson, and Ö. Dahl (Eds.), Proceedings of the Stockholm Workshop on 'Variation within Optimality Theory', pp. 111-120.

Hale, K. (1973). Deep-surface canonical disparities in relation to analysis and change: An australian example. In H. Hoenigswald and R. Longacre (Eds.), Current Trends in Linguistics, Volume 11, pp. 401-458. Mouton.

Hale, K. (1991). Remarks on Sanders "levelling in the history of polynesian passive formations". The Journal of the Polynesian Society 100(1), 99-101.

Hay, J. B., J. B. Pierrehumbert, A. J. Walker, and P. LaShell (2015). Tracking word frequency effects through 130 years of sound change. Cognition 139, 83-91.

Hockett, C. (1948). Potawatomi I: Phonemics, morphophonemics and morphological survey. International Journal of American Linguistics 14(1), 1-10.

Hockett, C. F. (1939). The Potawatomi Language. Ph. D. thesis, Yale University.

Jones, D. J. (1971). Odawa noun morphology. In J. Kaye, G. L. Piggott, and K. Tokaichi (Eds.), Odawa Language Project: First Report, Number 9 in Anthropological Series. Department of Anthropology, University of Toronto.

Kager, R. (1997). Rhythmic vowel deletion in Optimality Theory. In I. Roca (Ed.), Derivations and Constraints in Phonology, pp. 463-499. Oxford University Press.

Kaye, J. (1974). Morpheme structure constraints live! In Montreal Working Papers in Linguistics, Volume 3, pp. 55-62. McGill University.

Lockwood, H. T. (2017). How the Potawatomi Language Lives: A Grammar of Potawatomi. Ph. D. thesis, University of Wisconsin-Madison.

McCarthy, J. (2008). The serial interaction of stress and syncope. Natural Language and Linguistic Theory 26, 499-546.

Medler, A. (1998). Weshki-bmaadzijig ji-noondmowaad: 'That the Young Might Hear' The Stories of Andrew Medlar As Recorded by Leonard Bloomfield. Centre for Research and Teaching of Canadian Native Languages. 
Nichols, J. and E. Nyholm (1995). A Concise Dictionary of Minnesota Ojibwe. University of Minnesota Press.

Nichols, J. D. (2015). The Ojibwe People's Dictionary.

Ohala, J. (1989). Sound change is drawn from a pool of synchronic variation. In L. E. Breivik and E. H. Jahr (Eds.), Language Change: Contributions to the Study of its Causes, pp. 173-198. Mouton de Gruyter.

Ohala, J. (1992). What's cognitive, what's not, in sound change. In G. Kellermann and M. Morrissey (Eds.), Diachrony within Synchrony: Language History and Cognition Papers from the International Symposium at the University of Duisburg, pp. 309-355. Frankfurt am Main.

Ohala, J. (1993). The phonetics of sound change. In C. Jones (Ed.), Historical Linguistics: problems and perspectives, pp. 237-278. Longman.

Piggott, G. L. (1974 [1980]). Aspects of Odawa Morphophonemics. Garland.

Piggott, G. L. (1983). Extrametricality and Ojibwa stress. In McGill Working Papers in Linguistics, Volume 1, pp. 80-118. McGill University.

R Core Team (2016). R: A Language and Environment for Statistical Computing. Vienna, Austria: R Foundation for Statistical Computing.

Rhodes, R. (1975). A preliminary report on the dialects of Eastern Ojibwa-Odawa. In Proceedings of the Seventh Algonquian Conference.

Rhodes, R. (1976). The Morphosyntax of the Central Ojibwa Verb. Ph. D. thesis, University of Michigan.

Rhodes, R. (1985a). Eastern Ojibwa-Chippewa-Ottawa Dictionary. Mouton.

Rhodes, R. (1985b). Lexicography and Ojibwa Vowel Deletion. The Canadian Journal of Linguistics 30 (4), 453-471.

Rhodes, R. (1996). Relative clauses in ottawa. In 28th Annual Meeting of the Algonquian Conference.

Rhodes, R. and L. Buszard-Welcher (1996). An intruder in a sugar camp is beaten off. Algonquian and Iroquoian Linguistics Memoir 13, 355-366. 
Symonds, M. R. E. and A. Moussalli (2011). A brief guide to model selection, multimodel inference and model averaging in behavioural ecology using Akaike's information criterion. Behavioural Ecology and Sociobiology 65, 1321.

Valentine, J. R. (1994). Ojibwe Dialect Relations. Ph. D. thesis, University of Texas, Austin.

Valentine, J. R. (2001). Nishnaabemwin Reference Grammar. Toronto: University of Toronto Press, Inc. 